\title{
Estrutura e aspectos da regeneração natural de Floresta Ombrófila Mista no Parque Estadual de Campos do Jordão, SP, Brasil
}

\author{
Rose Pereira Muniz de Souza ${ }^{1,3}$, Vinícius de Castro Souza ${ }^{1}$, Rodrigo Trassi Polisel ${ }^{2}$ e \\ Natália Macedo Ivanauskas ${ }^{2}$
}

Recebido: 6.05.2011; aceito: 24.07.2012

\begin{abstract}
Structure and aspects of natural regeneration of a Mixed Ombrophyllous Forest at Parque Estadual de Campos do Jordão, São Paulo State, Brazil). The objective of this study was to evaluate the floristics and structural differences between adult and regenerating components of a stretch of Mixed Ombrophyllous Forest at Parque Estadual de Campos do Jordão, within the scope of raising hypotheses on its successional trajectory. In order to sample the adult component $(\mathrm{CBH} \geq 15 \mathrm{~cm})$, 50 permanent plots of $10 \times 20 \mathrm{~m}$ were allotted while five sub-plots of $1 \times 1 \mathrm{~m}$ of the regenerating component $(\mathrm{h} \geq 30 \mathrm{~cm}$ and $\mathrm{CBH}<15 \mathrm{~cm}$ ) were allotted in each plot. In the adult component, 1,770 individuals were sampled, distributed in 58 species, 38 genus and 26 families $\left(\mathrm{H}^{\prime}=3.08\right.$ and $\left.\mathrm{J}=0.73\right)$. In the regenerating component, 576 individuals, 55 species, 39 genus and 23 families $\left(\mathrm{H}^{\prime}=3.41\right.$ and $\left.\mathrm{J}=0.84\right)$ were sampled. We have concluded that procedures for conservation of the coniferous are needed.
\end{abstract}

Key words: Araucaria angustifolia, phytogeography, phytosociology, regeneration, understorey

RESUMO - (Estrutura e aspectos da regeneração natural de Floresta Ombrófila Mista no Parque Estadual de Campos do Jordão, SP, Brasil). O estudo buscou avaliar diferenças florísticas e estruturais entre os componentes adulto e regenerante de trecho de Floresta Ombrófila Mista em Campos do Jordão, a fim de levantar hipóteses sobre sua trajetória sucessional. Para amostragem do componente adulto $(\mathrm{CAP} \geq 15 \mathrm{~cm})$ foram instaladas 50 parcelas permanentes de $10 \times 20 \mathrm{~m}$ e, em cada uma dessas, cinco subparcelas de $1 \times 1 \mathrm{~m}$ para amostragem do componente regenerante $(\mathrm{h} \geq 30 \mathrm{~cm}$ e CAP $<15 \mathrm{~cm})$. No componente adulto foram amostrados 1.770 indivíduos, distribuídos em 58 espécies, 38 gêneros e 26 famílias $\left(\mathrm{H}^{\prime}=3,08\right.$ e $\mathrm{J}=0,73)$. Já entre os regenerantes foram observados 576 indivíduos, 55 espécies, 39 gêneros e 23 famílias $\left(\mathrm{H}^{\prime}=3,41\right.$ e $\mathrm{J}=0,84)$. Constatou-se que são necessárias ações de manejo para a conservação in situ das coníferas locais.

Palavras-chave: Araucaria angustifolia, dinâmica, fitogeografia, fitossociologia, sucessão natural

\section{Introdução}

A Floresta Ombrófila Mista é uma região fitoecológica típica do Sul do Brasil, presente em área contínua nos Estados do Rio Grande do Sul, Santa Catarina e Paraná (Veloso 1992). No entanto, algumas manchas disjuntas são encontradas em áreas de maior altitude na região Sudeste, é o caso do planalto de Campos do Jordão, que se configura como uma paisagem de exceção, inserida em região caracterizada por formações tropicais (Ab'Sáber 1977).

A partir do século XX, a exploração madeireira, a substituição da vegetação pela agropecuária e a ampliação das zonas urbanas provocaram a redução da área originalmente ocupada por Floresta Ombrófila Mista. Estima-se que os remanescentes de Floresta Ombrófila Mista, nos estágios primários ou mesmo avançados, não perfazem mais do que $0,7 \%$ da área original em território brasileiro (Medeiros et al. 2005). No Estado de São Paulo, a Floresta Ombrófila Mista recobre 174.681 ha, mas $80 \%$ da área corresponde à vegetação secundária (Kronka et al. 2005). Esse cenário resultou na inclusão do ecossistema na categoria de criticamente ameaçado e sua espécie típica, Araucaria angustifolia (Bert.) O. Kuntze, foi considerada em perigo de extinção (Medeiros et al. 2005).

1. Universidade de São Paulo, Escola Superior de Agricultura “Luiz de Queiroz”, Departamento de Ciências Biológicas, Herbário E.S.A., Av. Pádua Dias, 11, Caixa Postal 9, 13418-900 Piracicaba, SP, Brasil

2. Instituto Florestal, Seção de Ecologia, Rua do Horto, 931, 02377-000 São Paulo, SP, Brasil

3. Autor para correspondência: rpmsouza@yahoo.com.br 
O processo de sucessão da Floresta Ombrófila Mista está relacionado com a dinâmica populacional da Araucaria angustifolia. Essa espécie é emergente e determinante da fisionomia da vegetação que, ao colonizar áreas abertas ou campos, cria condições de umidade e fertilidade do solo que facilitam o recrutamento de outras espécies de plantas. No entanto, com o pleno desenvolvimento do subosque, os indivíduos adultos de araucária passam a ser encontrados somente nos estratos superiores, porque as condições de sombreamento impedem o recrutamento de novos indivíduos dessa espécie (Solórzano-Filho \& Kraus 1999).

O conhecimento sobre a estrutura, composição e dinâmica da Floresta Ombrófila Mista ainda é incipiente, sobretudo para os remanescentes paulistas. A maioria dos estudos sobre a Floresta Ombrófila Mista foi realizada no sul do Brasil, em sua área core de ocorrência, como demonstrado por Sanquetta \& Mattei (2006). Uma boa síntese sobre a composição florística e a estrutura dessas comunidades é apresentada em Jarenkow \& Budke (2009).

Nas áreas disjuntas da região sudeste do Brasil foram realizados estudos florísticos na Serra da Mantiqueira em Minas Gerais (Meireles et al. 2008) e levantamentos florísticos (Robim et al. 1990) e fitossociológicos (Los 2004) em São Paulo, sendo esses os únicos trabalhos realizados em Floresta Ombrófila Mista em território paulista. Dessa maneira, visando preencher parte da lacuna de conhecimentos sobre a Floresta Ombrófila Mista, teve início o projeto temático para o estudo da Floresta Ombrófila Mista no Estado de São Paulo (Cardoso 2004, Ivanauskas 2007). Adotando o mesmo protocolo de amostragem para a comunidade arbórea, foram avaliados trechos florestais na Serra da Bocaina, nas Bacias Hidrográficas do Alto Ribeira e do Alto Paranapanema.

Como parte do projeto temático, este estudo tem por objetivo avaliar a florística e a estrutura dos componentes adulto e regenerante de trecho de Floresta Ombrófila Mista na Serra da Mantiqueira para, assim, levantar hipóteses sobre a sua trajetória sucessional.

\section{Material e métodos}

O planalto de Campos do Jordão localiza-se na Serra da Mantiqueira, caracterizada por relevo declivivoso com altitudes entre 1.000 e $2.000 \mathrm{~m}$ (Modenesi 1988). O Parque Estadual de Campos do Jordão (PECJ), criado em 1941, possui 8.172 ha e localiza-se no município de Campos do Jordão, Nordeste do Estado de São Paulo.

O clima regional é temperado brando sem estiagem (Cfb), segundo o sistema de Köppen (Seibert et al. 1975). Os aspectos climáticos que caracterizam e diferenciam a região referem-se às amplitudes entre temperaturas máximas e mínimas, tanto anuais quanto diárias, e a ocorrência de geadas (Modenesi 1988). $\mathrm{O}$ mês mais quente é fevereiro, com temperatura média de $22,5^{\circ} \mathrm{C}$ e as temperaturas mais baixas são observadas de maio a agosto, com médias entre $15^{\circ} \mathrm{C}$ e $16,7^{\circ} \mathrm{C}$ (período observado de 1961 a 1990 , Sentelhas et al. 1999). No entanto, no inverno (julho) foi registrada temperatura média de $9,5^{\circ} \mathrm{C}$ (julho) e mínima absoluta de $-4,4{ }^{\circ} \mathrm{C}$ (Seibert et al. 1975).

A posição interiorana da Serra da Mantiqueira em relação à Serra do Mar reduz, em parte, os efeitos das chuvas produzidas pela umidade proveniente do Oceano Atlântico (Seibert et al. 1975). A precipitação anual média é de $1.891 \mathrm{~mm}$, variando entre $1.500 \mathrm{e}$ $2.000 \mathrm{~mm}$. O período chuvoso estende-se de outubro a março, seguido de período com menores precipitações, sendo julho e agosto os meses mais secos (Seibert et al. 1975).

Na região de Campos do Jordão os trechos de Floresta Ombrófila Mista estão restritos aos fundos de vale, sendo os interflúvios ocupados por campos naturais (Seibert et al. 1975). Assim, selecionou-se como área de estudo a floresta de fundo de vale e meia encosta que margeia o Córrego Galharada, no interior do Parque Estadual de Campos do Jordão. Parcelas foram distribuídas de acordo com o espaço disponível ao longo das margens do córrego, em trecho de floresta em bom estado de conservação ( $22^{\circ} 41^{\prime} 30^{\prime \prime} \mathrm{S}, 4^{\circ} 27^{\prime} 52^{\prime \prime} \mathrm{W}$ e $1.467 \mathrm{~m}$ de altitude). O solo foi classificado como Latossolo Vermelho Amarelo distrófico, textura argilosa (Barreta 2007).

A dificuldade em avaliar os componentes adulto e regenerante em florestas deve-se a falta de critérios padronizados para a amostragem. A diversidade de hábitos e formas de vida, assim como a definição de estratos, variam entre autores. Revisão sobre o assunto foi publicada por Parker \& Brown (2000), segundo os quais existem dez formas de conceituar a estratificação florestal. Neste trabalho optou-se por subdividir a floresta em dois componentes: adulto e regenerante.

Foram considerados como adultos todas as árvores e arbustos com circunferência a altura do peito $(1,3 \mathrm{~m})$ superior ou igual a $15 \mathrm{~cm}(\mathrm{CAP} \geq 15 \mathrm{~cm})$, que é o padrão para a amostragem do componente arbóreo em florestas tropicais (Caiafa \& Martins 2007). Para 
os indivíduos que perfilharam abaixo de $1,30 \mathrm{~m}$ de altura do solo, foram incluídos somente aqueles que atenderam ao critério de inclusão para pelo menos uma de suas ramificações. Trata-se de critério artificial, pois nem todos os indivíduos aqui denominados adultos podem ter atingido a fase reprodutiva.

No componente regenerante foram amostrados todos os indivíduos arbustivos ou arbóreos com altura $\geq 30 \mathrm{~cm}$ e CAP $<15 \mathrm{~cm}$. Como objetivou-se amostrar somente indivíduos jovens daqueles que futuramente iriam ocupar o componente adulto, foram contabilizados como regenerantes os indivíduos das espécies que já tivessem sido registradas no componente adulto. Para as espécies ausentes nesse componente, essas foram incluídas na amostragem caso tivessem sido registradas em outros levantamentos fitossociológicos com o mesmo critério de inclusão ou cujo o autor confirmasse o potencial da espécie em atingir porte elevado. Sendo assim, foram excluídos da análise de regenerantes os subarbustos e arbustos de pequeno porte, trepadeiras e ervas. Essas formas de vida foram tema de estudo da Dissertação de Mestrado de Polisel (2011).

Para a amostragem do componente adulto foram utilizadas 50 parcelas de $10 \times 20 \mathrm{~m}$, totalizando um hectare. Para a amostragem do componente regenerante foram instaladas, no interior de cada parcela de $10 \times 20 \mathrm{~m}$, cinco subparcelas de $1 \times 1 \mathrm{~m}$, a fim de obter amostra representativa de $5 \mathrm{~m}^{2}$ do estrato inferior de cada parcela (total de $250 \mathrm{~m}^{2}$ hectare ${ }^{-1}$ ). $\mathrm{O}$ posicionamento das subparcelas foi definido por sorteio das coordenadas do vértice superior esquerdo, tendo como referência as laterais da parcela de $10 \times 20 \mathrm{~m}$, tidas como eixos cartesianos. Para medida dessas coordenadas no campo, foi utilizado um Vertex.

Para todos os indivíduos adultos amostrados, foram anotados os valores de CAP, altura total (estimada visualmente) e a identificação da espécie. Para os regenerantes, foram registrados os valores de altura e a espécie. Nos casos em que não foi possível a identificação em campo, coletou-se material botânico e foram registradas observações para posterior identificação (características da casca, cores de flor e fruto, aroma, presença de exsudatos, entre outros).

O material botânico foi numerado, prensado, desidratado e encaminhado para a Seção de Ecologia Florestal do Instituto Florestal, São Paulo, SP, onde foi identificado através de comparações com os materiais do acervo do herbário. As espécies foram identificadas ou morfotipadas por comparações com materiais contidos em herbários (ESA, SPSF, UEC, SPF e
HRCB), consultas a especialistas de reconhecida competência e por literatura especializada. As coletas férteis foram incorporadas ao acervo do herbário da Escola Superior de Agricultura "Luiz de Queiroz"/USP (ESA), com duplicatas no herbário do Instituto Florestal (SPSF). Foi adotado o sistema de classificação proposto por Angiosperm Phylogeny Group II (Souza et al. 2008).

A fim de avaliar o esforço amostral empregado em cada componente utilizou-se, como critério para análise, o número de indivíduos que representasse $70 \%$ do total de indivíduos amostrados no componente regenerante. $\mathrm{O}$ mesmo número de indivíduos foi selecionado aleatoriamente no componente adulto. Dessa maneira foram obtidas as curvas de acumulação das espécies, independente da ordem de entrada dos dados e com tamanho amostral idêntico. A curva foi calculada por reamostragem com 10.000 interações e intervalos de confiança de $95 \%$. A reamostragem foi realizada com o aplicativo EcoSim 7.0 (Gotelli \& Colwell 2001). Com essas simulações obteve-se a curva espécie-indivíduo média e os intervalos de confiança empíricos $(95 \%)$ para a comparação entre os dois componentes.

Para cada distribuição do número de indivíduos em classes de tamanho foi calculada a função exponencial negativa $\left(\mathrm{y}=\mathrm{a} \cdot \mathrm{e}^{\mathrm{b} \mathrm{bx}}\right)$, onde $\mathrm{y}$ : número de indivíduos e x: classe de tamanho (Soares et al. 2007). $\mathrm{O}$ ajuste dos valores observados aos esperados foi testado pelo teste de Kolmogorov-Smirnov (Sokal \& Rohlf 1981), para verificar se a distribuição do número de indivíduos observados diferia daquela em que a distribuição de classes de tamanho seguiria o formato de "J-invertido".

A metodologia utilizada por Gomes (1992) e Ivanauskas \& Rodrigues (2000) foi aplicada para obter a taxa de perfilhamento, a fim de verificar se havia diferença para esse parâmetro entre estratos. Nos cálculos, foram utilizados todos os indivíduos amostrados no levantamento fitossociológico, sendo considerados perfilhados aqueles que apresentaram mais de um tronco a 1,30 m de altura do solo (nesse caso cada tronco foi denominado perfilho). Os indivíduos perfilhados foram distribuídos em relação ao número de perfilhos apresentados, com o objetivo de verificar a variação do número de perfilhos por indivíduo e por espécie. Foram calculadas as médias de indivíduos perfilhados por espécie $(\mathrm{Mp})$, por meio da relação entre o número total de perfilhos de cada espécie (P) e o seu número total de indivíduos (Ni); e a proporção entre indivíduos perfilhados e não 
perfilhados por espécie (Pip), por meio da relação entre o número de indivíduos que perfilharam a $1,30 \mathrm{~m}$ de altura do solo (Ip) e o número total de indivíduos de cada espécie $(\mathrm{Ni})$.

Os parâmetros fitossociológicos calculados foram aqueles descritos para o método de parcelas em Martins (1991) e obtidos utilizando os programas do pacote FITOPAC (Shepherd 1994). O índice do valor de importância ecológico de espécie (VI) foi calculado pela somatória da frequência, densidade e dominância relativas, descritos por Whittaker (1972) e Mueller-Dombois \& Ellemberg (1974).

Como medida de diversidade utilizou-se o índice de Shannon (Mueller-Dombois \& Ellenberg 1974) calculado com base no logaritmo natural e a equabilidade de Pielou (Pielou 1966). Para a análise da similaridade florística entre os componentes adulto e regenerante, foram utilizados os índices de Sorensen e de Jaccard (Valentin 2000).

As espécies registradas nos inventários fitossociológicos dos componentes regenerante e adulto foram usadas para produzir a matriz de densidade de espécies por parcela de $10 \times 20 \mathrm{~m}$. A partir dessa matriz foram obtidas as curvas da acumulação das espécies, independente da ordem de entrada dos dados. Para isso, foram feitas permutações dos indivíduos, gerando 1.000 simulações com ordem aleatória em cada um dos casos (Efron \& Tibshirani 1993). Com essas simulações obteve-se a curva espécie $\times$ indivíduo média e os intervalos de confiança empíricos (95\%).

Os estimadores não-paramétricos de riqueza de espécies Chao e Bootstrap (Colwell \& Coddington 1994, Magurran 2004), foram calculados pelo pacote Vegan (Community Ecology Packa) do programa estatístico R (R Development Core Team 2008). Essa abordagem produz estimativas de riqueza de espécies baseadas por unidade de área (amostras) e estimativas baseadas no número de indivíduos amostrados (Gotelli \& Colwell 2001). O índice Chao é mais sensível quando ocorre agrupamento das espécies, devido a utilização da abundância para os cálculos, diferente do estimador Bootstrap (boot) que é baseado em dados de incidência o que o torna mais sensível ao tamanho da amostra (Chazdon et al. 1998).

\section{Resultados}

A curva de rarefação (acumulação de espécies) obtida neste estudo iniciou a estabilização com aproximadamente 1.200 indivíduos amostrados no componente adulto e 400 indivíduos no componente regenerante, portanto houve suficiência amostral.
No componente adulto, a área basal total foi de $53,60 \mathrm{~m}^{2} \mathrm{ha}^{-1}$ e foram amostrados 1.921 ind ha $^{-1}$, dos quais $7,7 \%$ estavam mortos em pé (151 ind ha- $\left.{ }^{-1}\right)$. No componente regenerante a densidade total foi maior, com 23.040 ind ha ${ }^{-1}$ e 280 ind ha ${ }^{-1}$ mortos $(1,1 \%$ do total).

Os indivíduos amostrados no componente adulto podem ser subdivididos em quatro classes de altura: o subosque com indivíduos menores que $4 \mathrm{~m}$, o subdossel com arvoretas de 4-10 m, dossel com indivíduos de 10-16 m e árvores emergentes superiores a $16 \mathrm{~m}$ (figura 1a).

A distribuição diamétrica dos indivíduos do componente adulto não se assemelhou ao modelo exponencial negativo (figura $1 b$ ) e as distribuições entre classes não foram significativas $(p<0,01)$. A maior parte dos indivíduos (43\%) apresentou diâmetros entre 4,77 e 9,77 cm, sendo comum espécies com alta densidade e elevado perfilhamento, como é o caso de Myrcengenia miersiana, Drimys brasiliensis e Myrcia hartwegiana. Entre as 32 espécies registradas com algum grau de perfilhamento $(55 \%$ da riqueza total), 12 são mirtáceas típicas de subosque, a maior parte com dois ou três perfilhos, mas com registro de até oito perfilhos em um mesmo indivíduo (tabela 1). No componente regenerante mais de $55 \%$ dos indivíduos estão na classe de altura entre 30 e $80 \mathrm{~cm}$ (figura 2).

Do total de 2.494 indivíduos amostrados em ambos os componentes, foram identificadas 82 espécies, pertencentes a 46 gêneros e 31 famílias, com duas morfo-espécies (tabela 2). No componente adulto os 1.770 indivíduos vivos pertenciam a 26 famílias, 38 gêneros e 56 espécies. Já no componente regenerante foram amostrados 576 indivíduos, distribuídos em 23 famílias, 39 gêneros e 53 espécies.

Os dois componentes avaliados apresentaram flora muito semelhante, com 25 espécies em comum e mais de $28 \%$ de similaridade pelo índice de Jaccard e acima de $40 \%$ no índice de Sorensen.

Entre as espécies de maior interesse para a conservação presentes no local destacam-se Araucaria angustifolia e Dicksonia sellowiana, categorizadas como ameaçadas de extinção pelo IBAMA (2008) e, juntamente com Siphoneugena reitzii, como vulneráveis na lista oficial de espécies da flora do Estado de São Paulo (SMA 2004).

Algumas famílias foram exclusivas do componente adulto: Cardiopteridaceae, Celastraceae, Clethraceae, Fabaceae, Styracaceae, Verbenaceae e Vochysiaceae (juntas perfazem 1,08\% do total de indivíduos e 5,8\% do total de espécies). No componente regenerante as 
exclusivas foram Cyatheaceae, Meliaceae, Rubiaceae e Sapindaceae $(6,25 \%$ e $5,0 \%$ respectivamente do total de indivíduos e espécies). Myrtaceae foi a família de maior riqueza em ambos os componentes, com valor muito superior às demais famílias com elevado número de espécies na área (figura 3 ).

As espécies de baixa densidade ( 1 ind ha $\left.{ }^{-1}\right)$ representaram $17 \%$ do total de espécies do componente adulto, enquanto as de alta densidade (mais de 11 ind ha ${ }^{-1}$ ) somaram 36\% (tabela 3). Entre as de alta densidade, Myrceugenia miersiana, Drimys brasiliensis, Myrcia hartwegiana, Prunus myrtifolia, Cinnamomum sellowianum e Myrsine umbellata foram registradas tanto no componente adulto quanto no componente regenerante, portanto essas populações devem manter-se em destaque na comunidade por
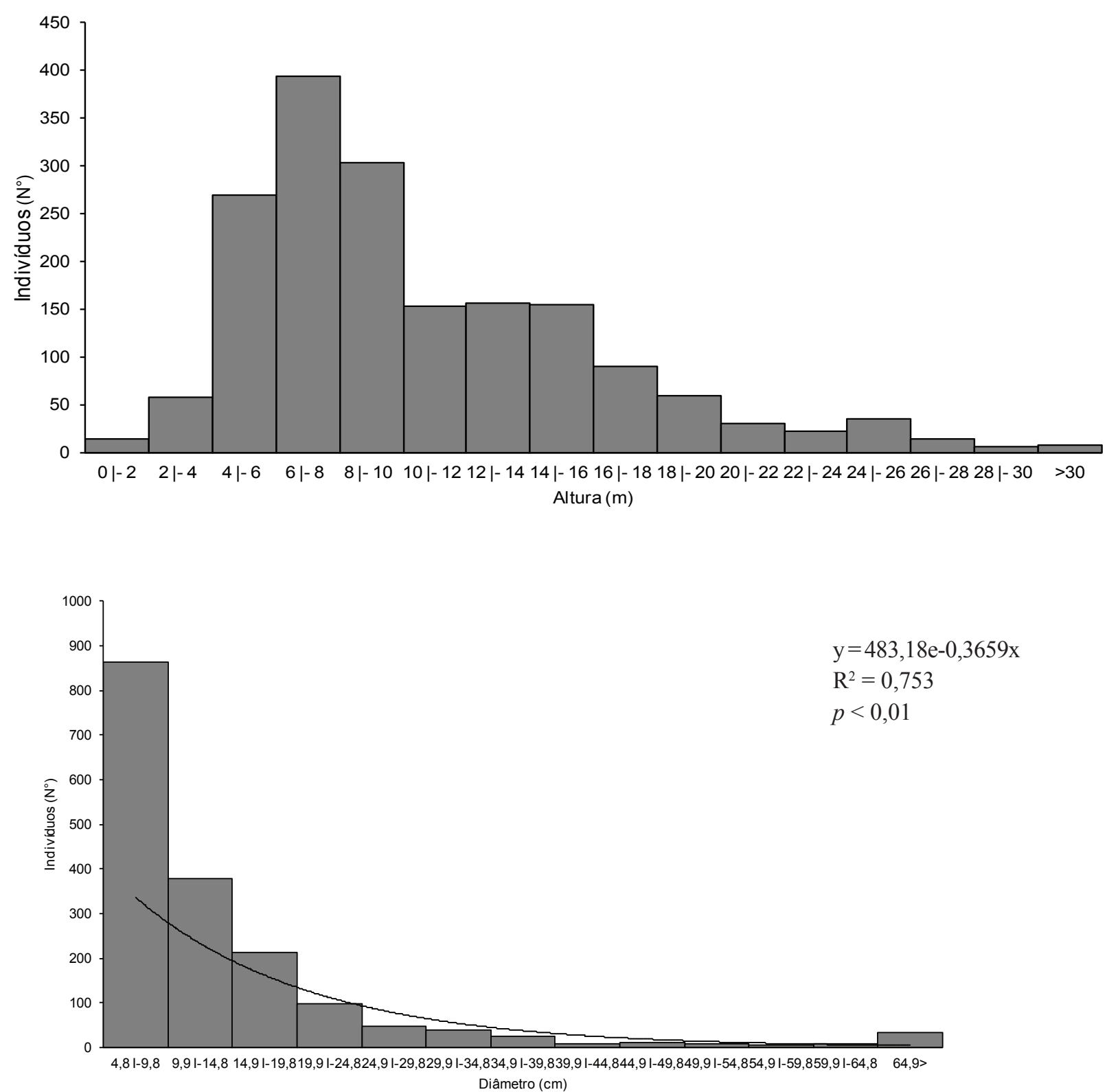

Figura 1. Distribuição dos indivíduos arbóreos do componente adulto amostrados em trecho de Floresta Ombrófila Mista no Parque Estadual de Campos do Jordão, Campos do Jordão, SP, Brasil. a. Classes de altura; b. Classes de diâmetro, sendo que linha contínua representa a distribuição esperada do modelo exponencial negativo.

Figure 1. Tree distribution from the adult component sampled in a stand of Mixed Ombrophilous Forest, at Parque Estadual de Campos do Jordão, Campos do Jordão, São Paulo State, Brazil. a. Height classes; b. Diameter classes. Continuous line represents the distribution expected from the negative exponential model. 
longo prazo. Já Ocotea dispersa, Myrcia venulosa, Piptocarpha regnellii e Myrciaria tenella foram registradas somente no componente adulto, portanto não apresentam evidências de regeneração na área.

Symplocos celastrinea e Endlicheria paniculata também foram registradas somente no componente regenerante, onde foram amostradas em elevada densidade. No entanto, não se tratam de populações jovens, inclusive porque Symplocos celastrinea foi registrado na fase reprodutiva. Pode-se concluir que em Campos do Jordão essas espécies são de pequeno porte e típicas de subosque, portanto não deveriam ter sido incluídas na amostragem do componente regenerante. $\mathrm{O}$ fato de indivíduos adultos terem sido amostrados resulta do critério de inclusão artificial: essas duas espécies foram relatadas em outros estudos

Tabela 1. Espécies que apresentaram perfilhamento, em ordem decrescente de Mp (média de perfilhos por espécie) em levantamento fitossociológico em um trecho de Floresta Ombrófila Mista no Parque Estadual de Campos do Jordão, Campos do Jordão, SP, Brasil. Ni: número total de indivíduos; Ip: número de indivíduos que apresentaram perfilhamento; P: número total de perfilhos; Mp: média de perfilhos por espécie; Pip: proporção de indivíduos perfilhados por espécie.

Table 1. Tillering species in the decreasing order of Mp (average tiller species) from the phytosociological survey in a stand of Mixed Ombrophilous Forest, at Parque Estadual de Campos do Jordão, Campos do Jordão, São Paulo State, Brazil. Ni: number of individuals; Ip: number of individuals with tillering; P: tiller number; Mp: average tillering per species; Pip: proportion of tillering individuals per species.

\begin{tabular}{|c|c|c|c|c|c|c|c|c|c|c|c|c|}
\hline \multirow[t]{2}{*}{ Nome Científico } & \multirow[t]{2}{*}{$\mathrm{Ni}$} & \multirow[t]{2}{*}{ Ip } & \multicolumn{7}{|c|}{$\begin{array}{l}\text { Distribuição de Indivíduos } \\
\text { (Ip) Número de perfilhos }\end{array}$} & \multirow[t]{2}{*}{$\mathrm{P}$} & \multirow[t]{2}{*}{$\mathrm{Mp}\left(\mathrm{P} \mathrm{Ni}^{-1}\right)$} & \multirow[t]{2}{*}{ Pip $\left(\mathrm{Ip} \mathrm{Ni}^{-1}\right)$} \\
\hline & & & 2 & 3 & 4 & 5 & 6 & 7 & 8 & & & \\
\hline Myrcia laruotteana & 62 & 32 & 18 & 10 & 2 & 1 & 1 & 0 & 0 & 85 & 1,37 & 0,52 \\
\hline Myrcia hartwegiana & 165 & 68 & 34 & 19 & 5 & 6 & 4 & 0 & 0 & 199 & 1,21 & 0,41 \\
\hline Ilex theezans & 6 & 3 & 3 & 0 & 0 & 0 & 0 & 0 & 0 & 6 & 1,00 & 0,50 \\
\hline Myrceugenia ovata & 7 & 3 & 2 & 1 & 0 & 0 & 0 & 0 & 0 & 7 & 1,00 & 0,43 \\
\hline Ilex pseudobuxus & 9 & 2 & 1 & 1 & 0 & 0 & 0 & 0 & 0 & 5 & 0,56 & 0,22 \\
\hline Myrciaria tenella & 13 & 4 & 2 & 1 & 0 & 0 & 0 & 0 & 0 & 7 & 0,54 & 0,31 \\
\hline Myrceugenia sp. 2 & 25 & 6 & 5 & 1 & 0 & 0 & 0 & 0 & 0 & 13 & 0,52 & 0,24 \\
\hline Miconia cinerascens & 4 & 1 & 1 & 0 & 0 & 0 & 0 & 0 & 0 & 2 & 0,50 & 0,25 \\
\hline Vernonanthura discolor & 4 & 1 & 1 & 0 & 0 & 0 & 0 & 0 & 0 & 2 & 0,50 & 0,25 \\
\hline Myrceugenia miersiana & 400 & 73 & 48 & 15 & 5 & 2 & 1 & 0 & 2 & 193 & 0,48 & 0,18 \\
\hline Jacaranda puberula & 33 & 6 & 6 & 0 & 0 & 0 & 0 & 0 & 0 & 12 & 0,36 & 0,18 \\
\hline Picramnia parvifolia & 23 & 4 & 4 & 0 & 0 & 0 & 0 & 0 & 0 & 8 & 0,35 & 0,17 \\
\hline Styrax leprosus & 6 & 1 & 1 & 0 & 0 & 0 & 0 & 0 & 0 & 2 & 0,33 & 0,17 \\
\hline Siphoneugena reitzii & 12 & 1 & 0 & 1 & 0 & 0 & 0 & 0 & 0 & 3 & 0,25 & 0,08 \\
\hline Ocotea dispersa & 34 & 4 & 4 & 0 & 0 & 0 & 0 & 0 & 0 & 8 & 0,24 & 0,12 \\
\hline Drimys brasiliensis & 172 & 17 & 16 & 1 & 0 & 0 & 0 & 0 & 0 & 35 & 0,20 & 0,10 \\
\hline Ilex microdonta & 21 & 2 & 2 & 0 & 0 & 0 & 0 & 0 & 0 & 4 & 0,19 & 0,10 \\
\hline Myrceugenia sp. 3 & 22 & 2 & 2 & 0 & 0 & 0 & 0 & 0 & 0 & 4 & 0,18 & 0,09 \\
\hline Dasyphyllum spinescens & 11 & 1 & 1 & 0 & 0 & 0 & 0 & 0 & 0 & 2 & 0,18 & 0,09 \\
\hline Prunus myrtifolia & 93 & 6 & 4 & 0 & 2 & 0 & 0 & 0 & 0 & 16 & 0,17 & 0,06 \\
\hline Cinnamomum sellowianum & 92 & 7 & 6 & 1 & 0 & 0 & 0 & 0 & 0 & 15 & 0,16 & 0,08 \\
\hline Annona rugulosa & 78 & 5 & 4 & 0 & 1 & 0 & 0 & 0 & 0 & 12 & 0,15 & 0,06 \\
\hline Myrsine umbellata & 86 & 6 & 6 & 0 & 0 & 0 & 0 & 0 & 0 & 12 & 0,14 & 0,07 \\
\hline Piptocarpha regnellii & 15 & 1 & 1 & 0 & 0 & 0 & 0 & 0 & 0 & 2 & 0,13 & 0,07 \\
\hline Myrcia venulosa & 17 & 1 & 1 & 0 & 0 & 0 & 0 & 0 & 0 & 2 & 0,12 & 0,06 \\
\hline Symplocus falcata & 58 & 3 & 3 & 0 & 0 & 0 & 0 & 0 & 0 & 6 & 0,10 & 0,05 \\
\hline Podocarpus lambertii & 53 & 1 & 1 & 0 & 0 & 0 & 0 & 0 & 0 & 2 & 0,04 & 0,02 \\
\hline
\end{tabular}


com porte mais elevado (Bergamim \& Mondin 2006, Kozera et al. 2005a, Reginato \& Goldenberg 2007, Aranha Filho 2008), portanto com potencial para atingir o critério de inclusão estabelecido neste estudo para o componente adulto (circunferência a $1,30 \mathrm{~m}$ altura do solo igual ou superior a $15 \mathrm{~cm}$ ).

As coníferas Podocarpus lambertii e Araucaria angustifolia destacaram-se no componente adulto devido ao porte elevado dos indivíduos amostrados (figura 4a) que determinaram altos valores de dominância. Esse resultado já era esperado, pois as espécies são marcadoras da fisionomia de Floresta Ombrófila Mista, onde alcançam diâmetros elevados e ocorrem como emergentes (figura 4a). No entanto, no componente regenerante as espécies não apresentaram o mesmo destaque em valor de importância (tabela 4 e figura $4 \mathrm{~b}$ ), pois apresentaram os mais baixos valores de densidade ( 40 e 80 ind $\mathrm{ha}^{-1}$ ) comparados às demais espécies que compartilham o mesmo ambiente.

Entre as angiospermas, as espécies de maior valor de importância no componente adulto também ocuparam as primeiras posições no componente regenerante (figura 4), com exceção de Drimys brasiliensis e Annona rugulosa que, embora tenham apresentado valores de densidade superiores aos das coníferas ( 880 e 200 ind ha ${ }^{-1}$ ), também não constam entre as de maior valor de densidade no componente regenerante, as quais apresentam valores superiores a 1.120 ind ha ${ }^{-1}$.
A diversidade de espécies para o componente adulto $\left(\mathrm{H}^{\prime}=3,08\right)$ foi menor comparada ao componente regenerante $\left(\mathrm{H}^{\prime}=3,41\right)$. Isso porque $\mathrm{o}$ valor de equabilidade foi mais alto $\left(\mathrm{J}^{\prime}=0,84\right)$ entre os regenerantes, indicando que nesse estrato as espécies contribuem de maneira mais uniforme para o índice de diversidade quando comparado ao estrato dominante $\left(\mathrm{J}^{\prime}=0,73\right)$. A baixa equabilidade no componente adulto deve-se ao tamanho das populações de Myrceugenia miersiana, Drimys brasiliensis e Myrcia hartwegiana (figura 4a).

As curvas de riqueza geradas por rarefação apóiam a idéia de que as duas classes sustentariam os mesmos níveis de riqueza, pois houve grande sobreposição dos intervalos de confiança ao longo de toda a curva (figura 5). Os estimadores não-paramétricos utilizados para os dois componentes produziram estimativas que se aproximaram do valor de riqueza observado para a comunidade total (tabela 4), sendo que para o índice de Boot as estimativas possuem valores ligeiramente superiores.

\section{Discussão}

A flora da Floresta Ombrófila Mista é fortemente influenciada pelas baixas temperaturas e pela ocorrência regular de geadas no inverno (Roderjan et al. 2002). Em São Paulo, o clima temperado e a sazonalidade de temperaturas, com incidência de geadas em trechos de elevadas altitudes da Serra

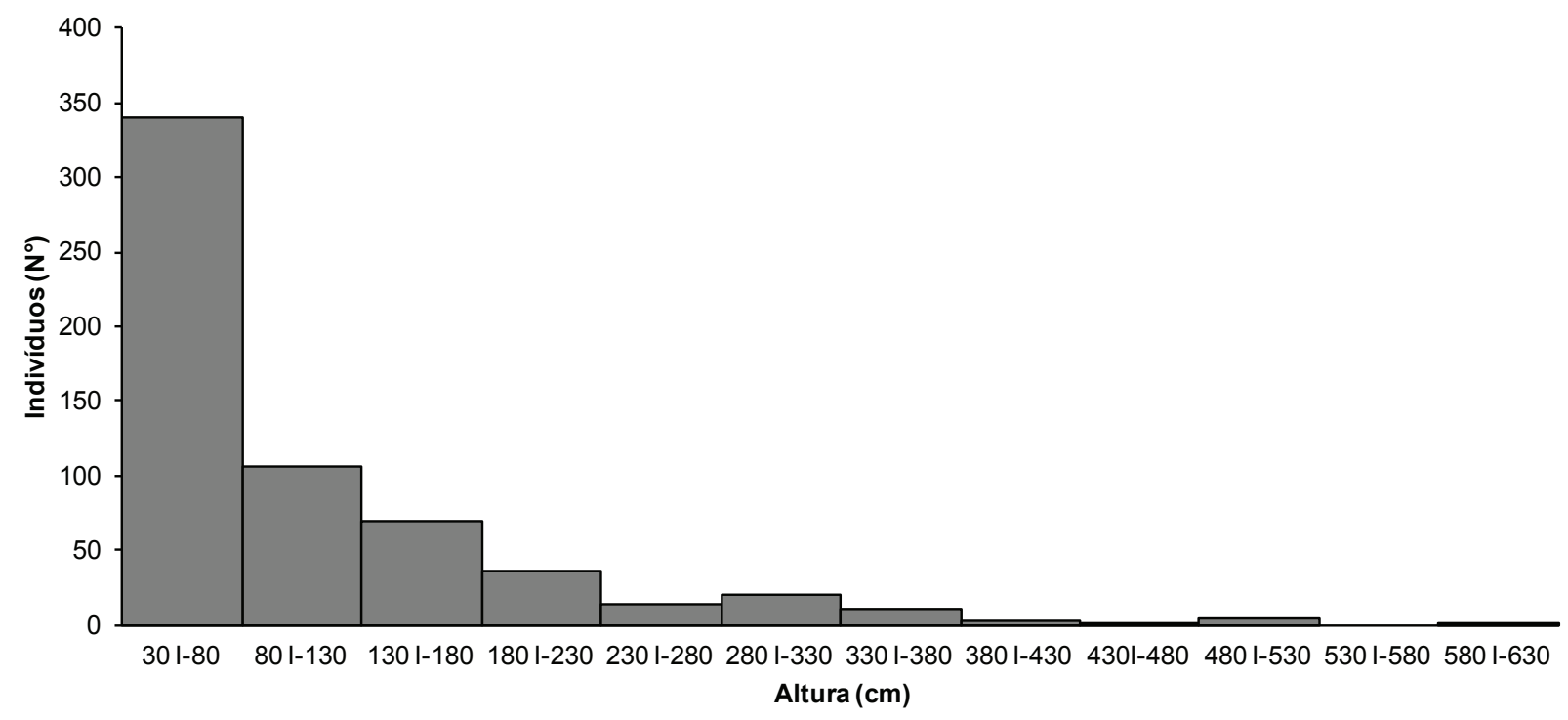

Figura 2. Distribuição do número de indivíduos arbóreos no estrato inferior (maiores que $30 \mathrm{~cm}$ de altura e DAP $<5$ ), por classe de altura, amostrados em trecho de Floresta Ombrófila Mista no Parque Estadual de Campos do Jordão, Campos do Jordão, SP, Brasil.

Figure 2. Tree distribution from lower layer $(\mathrm{DBH}<5 \mathrm{~cm}$ and $\mathrm{h} \geq 30 \mathrm{~cm})$, sorted by height classes, sampled in a stand of Mixed Ombrophilous Forest at Parque Estadual de Campos do Jordão Campos do Jordão, São Paulo State, Brazil. 
da Mantiqueira, permitem a ocorrência de espécies características da Floresta Ombrófila Mista, como é o caso de Araucaria angustifolia, Podocarpus lambertii, Drimys brasiliensis, Ilex theezans e Styrax leprosus, espécies comuns em florestas naturais de Campos do Jordão e que também ocorrem na região Sul do Brasil. Portanto, esse relicto de Floresta Ombrófila Mista na Serra da Mantiqueira compartilha da descrição florística de florestas amostradas no Sul do Brasil (Klein 1984, Jarenkow 1985, Nascimento et al. 2001).

A presença de espécies típicas da Floresta Ombrófila Mista corrobora a hipótese levantada por Ab'Sáber (1992), segundo o qual houve uma retração da vegetação arbórea em toda região Sul e Sudeste do Brasil, com exceção de áreas de refúgio em elevadas altitudes, como é o caso de Campos do Jordão. Além da flora, a floresta avaliada neste estudo também apresenta a fisionomia peculiar de uma típica Floresta
Ombrófila Mista, com as coníferas Podocarpus lambertii e Araucaria angustifolia destacando-se como emergentes. Associadas às espécies características do dossel, encontram-se muitas espécies latifoliadas de Lauraceae e Myrtaceae, amostradas tanto como árvores de grande porte quanto como arvoretas no subosque.

Myrtaceae e Lauraceae apresentam elevada riqueza não apenas em Florestas Ombrófilas Mistas, pois também são citadas em inventários em Florestas Ombrófilas Densas Montanas ou Submontanas de São Paulo e Rio de Janeiro (Mori et al. 1981, Struffaldi-de-Vuono 1985, Baitello et al. 1992, Nastri et al. 1992, Mantovani 1993, Arzolla 2002), com aumento em importância na comunidade de acordo com a maturidade da floresta (Tabarelli \& Mantovani 1999). Já Fabaceae, Meliaceae e Sapindaceae, amostradas com apenas uma espécie em Campos do

Tabela 2. Espécies registradas no levantamento fitossociológico do componente adulto (Ad, PAP $\geq 15 \mathrm{~cm}$ ) e regenerante $(\mathrm{Rg}, \mathrm{PAP}<15 \mathrm{~cm}$ e $\mathrm{h} \geq 30 \mathrm{~cm})$ de trecho de Floresta Ombrófila Mista no Parque Estadual de Campos do Jordão, Campos do Jordão, SP, Brasil.

Table 2. Species sampled in the phytossociological survey of the arboreal component (Ad. $\mathrm{PBH} \geq 15 \mathrm{~cm}$ ) and sapling component $(\mathrm{Rg}, \mathrm{PBH}<15 \mathrm{~cm}$ and $\mathrm{h} \geq 30 \mathrm{~cm})$ in a stand of Mixed Ombrophilous Forest, Parque Estadual de Campos do Jordão, Campos do Jordão, São Paulo State, Brazil.

\begin{tabular}{|c|c|c|c|c|c|}
\hline Família & Nome Científico & Nome Vulgar & Ad & $\mathrm{Rg}$ & $\mathrm{N}^{\mathrm{o}}$ Coletor \\
\hline \multirow[t]{3}{*}{ Annonaceae } & Guatteria australis A.St.-Hil. & & & $\mathrm{X}$ & \\
\hline & Porcelia macrocarpa (Warm.) R. E. Fr. & & & $\mathrm{X}$ & \\
\hline & Annona rugulosa (Schltdl.) H.Rainer & araticum & $\mathrm{X}$ & $\mathrm{X}$ & \\
\hline \multirow[t]{6}{*}{ Aquifoliaceae } & Ilex dumosa Reissek & & & $\mathrm{X}$ & \\
\hline & Ilex microdonta Reissek & caúna & $\mathrm{X}$ & $\mathrm{X}$ & rpms 03 \\
\hline & Ilex pseudobuxus Reissek & caúna-da-folha-miúda & $\mathrm{X}$ & & rpms 144 \\
\hline & Ilex taubertiana Loes. & & $\mathrm{X}$ & $\mathrm{X}$ & rpms 12 \\
\hline & Ilex theezans Mart. ex Reissek & orelha-de-mico, caúna & $\mathrm{X}$ & & \\
\hline & Ilex sp. & & & $\mathrm{X}$ & \\
\hline Araucariaceae & Araucaria angustifolia (Bertol) Kuntze & pinheiro-do-Paraná & $\mathrm{X}$ & $\mathrm{X}$ & rpms 53 \\
\hline \multirow[t]{9}{*}{ Asteraceae } & Baccharis oreophila Malme & & $\mathrm{X}$ & & \\
\hline & Dasyphyllum spinescens (Less.) Cabrera & & $\mathrm{X}$ & $\mathrm{X}$ & rpms 147 \\
\hline & Piptocarpha axilaris (Less.) Baker & & & $\mathrm{X}$ & \\
\hline & Piptocarpha macropoda (DC.) Baker & & $\mathrm{X}$ & & \\
\hline & Piptocarpha regnellii (Sch.Bip.) Cabrera & & $\mathrm{X}$ & & \\
\hline & Vernonanthura discolor (Spreng.) H.Rob. & vassourão-preto & $\mathrm{X}$ & & \\
\hline & Baccharis sp. & & & $\mathrm{X}$ & \\
\hline & Vernonanthura sp. & & & $\mathrm{X}$ & \\
\hline & Asteraceae & & & $\mathrm{X}$ & \\
\hline Bignoniaceae & Jacaranda puberula Cham. & caroba & $\mathrm{X}$ & $\mathrm{X}$ & \\
\hline Cardiopteridaceae & Citronella megaphylla (Miers) R.A. Howard & & $\mathrm{X}$ & & \\
\hline
\end{tabular}


Souza et al.: Estrutura de trecho da Floresta Ombrófila Mista, SP, Brasil 395

Tabela 2 (continuação)

\begin{tabular}{|c|c|c|c|c|c|}
\hline Família & Nome Científico & Nome Vulgar & Ad & $\operatorname{Rg}$ & $\mathrm{N}^{\circ}$ Coletor \\
\hline Celastraceae & Maytenus salicifolia Reissek & & $\mathrm{X}$ & & \\
\hline Clethraceae & Clethra scabra Pers. & carne-de-vaca & $\mathrm{X}$ & & \\
\hline Cyatheaceae & Cyathea atrovirens (Langsd. \& Fisch.) Domin & samambaiaçu & & $\mathrm{X}$ & \\
\hline Dicksoniaceae & Dicksonia sellowiana Hook. & xaxim & $\mathrm{X}$ & $\mathrm{X}$ & $\operatorname{rtp} 302$ \\
\hline Fabaceae & Mimosa scabrella Benth. & bracatinga & $\mathrm{X}$ & & rpms 01 \\
\hline Lamiaceae & Aegiphila integrifolia (Jacq.) Moldenke & tamanqueira & $\mathrm{X}$ & & rpms 136 \\
\hline \multirow[t]{8}{*}{ Lauraceae } & Cinnamomum sellowianum (Nees \& Mart.) Kosterm. & & $\mathrm{X}$ & $\mathrm{X}$ & \\
\hline & Endlicheria paniculata (Spreng.) J.F.Macbr. & canela-bosta & & $\mathrm{X}$ & \\
\hline & Ocotea bicolor Vattimo-Gil & & $\mathrm{X}$ & & \\
\hline & Ocotea dispersa (Nees \& Mart.) Mez & & $\mathrm{X}$ & & rpms 51 \\
\hline & Ocotea glaziovii Mez & & $\mathrm{X}$ & & rpms 145 \\
\hline & Ocotea puberula (Rich.) Nees & canela-guaica & $\mathrm{X}$ & $\mathrm{X}$ & \\
\hline & Persea willdenovii Kosterm. & & $\mathrm{X}$ & & $\operatorname{rtp} 207$ \\
\hline & Ocotea sp. & & $\mathrm{X}$ & & \\
\hline Melastomataceae & Miconia cinerascens Miq. & & $\mathrm{X}$ & $\mathrm{X}$ & rpms 141 \\
\hline Meliaceae & Cabralea canjerana (Vell.) Mart. & & & $\mathrm{X}$ & \\
\hline \multirow[t]{4}{*}{ Myrsinaceae } & Myrsine coriacea (Sw.) R.Br. ex Roem. \& Schult. & capororoca & $\mathrm{X}$ & & rpms 02 \\
\hline & Myrsine gardneriana A.DC. & capororoca & & $\mathrm{X}$ & \\
\hline & Myrsine umbellata Mart. & capororocão & $\mathrm{X}$ & $\mathrm{X}$ & \\
\hline & Myrsine villosissima A.DC. & & & $\mathrm{X}$ & \\
\hline \multirow[t]{19}{*}{ Myrtaceae } & Calyptranthes lucida Mart. ex DC. & & $\mathrm{X}$ & $\mathrm{X}$ & \\
\hline & Eugenia ligustrina (Sw.) Willd. & & $\mathrm{X}$ & $\mathrm{X}$ & \\
\hline & Myrcia retorta Cambess. & & $\mathrm{X}$ & & rpms 16 \\
\hline & $\begin{array}{l}\text { Myrceugenia brevipedicellata (Burret) D.Legrand \& } \\
\text { Kausel }\end{array}$ & & $\mathrm{X}$ & & \\
\hline & $\begin{array}{l}\text { Myrceugenia miersiana (Gardner) D.Legrand \& } \\
\text { Kausel }\end{array}$ & guamirim-da-várzea & $\mathrm{X}$ & $\mathrm{X}$ & \\
\hline & Myrceugenia myrcioides (Camb.) O. Berg & & $\mathrm{X}$ & & \\
\hline & Myrceugenia ovata (Hook. \& Arn.) O.Berg & & $\mathrm{X}$ & $\mathrm{X}$ & rpms 17 \\
\hline & Myrcia laruotteana Cambess. & & $\mathrm{X}$ & $\mathrm{X}$ & rpms 20 \\
\hline & Myrcia hartwegiana (O.Berg) Kiaersk. & & & & \\
\hline & Myrcia oligantha O.Berg & & $\mathrm{X}$ & $\mathrm{X}$ & \\
\hline & Myrcia splendens (Sw.) DC. & & $\mathrm{X}$ & & rpms 50 \\
\hline & Myrcia venulosa DC. & guamirim & $\mathrm{X}$ & & rpms 56 \\
\hline & Myrciaria floribunda (H.West ex Willd.) O.Berg & & & $\mathrm{X}$ & \\
\hline & Myrciaria tenella (DC.) O.Berg & cambuí & $\mathrm{X}$ & & rpms 55 \\
\hline & Siphoneugena reitzii D. Legrand & & $\mathrm{X}$ & $\mathrm{X}$ & \\
\hline & Myrceugenia sp. 1 & & & $\mathrm{X}$ & \\
\hline & Myrceugenia sp. 2 & & $\mathrm{X}$ & & \\
\hline & Myrceugenia sp. 3 & & $\mathrm{X}$ & & \\
\hline & Myrtaceae & & & $\mathrm{X}$ & \\
\hline \multirow[t]{2}{*}{ Picramniaceae } & Picramnia glazioviana Engl. & pau-amargo & $\mathrm{X}$ & & \\
\hline & Picramnia parvifolia Engl. & & $\mathrm{X}$ & $X$ & rpms 54 \\
\hline Podocarpaceae & Podocarpus lambertii Klotzsch ex Endl. & pinheiro-bravo & $\mathrm{X}$ & $X$ & contin \\
\hline
\end{tabular}


Tabela 2 (continuação)

\begin{tabular}{|c|c|c|c|c|c|}
\hline Família & Nome Científico & Nome Vulgar & $\mathrm{Ad}$ & $\operatorname{Rg}$ & $\mathrm{N}^{\mathrm{o}}$ Coletor \\
\hline Rhamnaceae & Rhamnus sphaerosperma $\mathrm{Sw}$. & & $\mathrm{X}$ & $\mathrm{X}$ & rpms 04 \\
\hline Rosaceae & Prunus myrtifolia (L.) Urb & pessegueiro-bravo & $\mathrm{X}$ & $\mathrm{X}$ & \\
\hline \multirow[t]{3}{*}{ Rubiaceae } & Psychotria longipes Müll.Arg. & & & $\mathrm{X}$ & \\
\hline & Rudgea jasminoides (Cham.) Müll.Arg. & & & $\mathrm{X}$ & \\
\hline & Rudgea parquioides Müll.Arg. & & & $\mathrm{X}$ & rtp 216 \\
\hline Rutaceae & Zanthoxylum rhoifolium Lam. & mamica-de-porca & $\mathrm{X}$ & $\mathrm{X}$ & \\
\hline Salicaceae & Casearia decandra Jacq. & guaçatonga & $\mathrm{X}$ & $\mathrm{X}$ & \\
\hline Sapindaceae & Cupania oblongifolia Mart. & cuvatã & & $\mathrm{X}$ & \\
\hline \multirow[t]{6}{*}{ Solanaceae } & Capsicum flexuosum Sendtn. & & & $\mathrm{X}$ & \\
\hline & Solanum argenteum Dunal & folha-prata & & $\mathrm{X}$ & \\
\hline & Solanum mauritianum Scop. & joá-de-árvore & $\mathrm{X}$ & & rpms 05 \\
\hline & Solanum pseudoquina A.St.-Hil. & maria-mole-graúda & $\mathrm{X}$ & $\mathrm{X}$ & rpms 143 \\
\hline & Solanum swartzianum Roem. \& Schult & folha-prata & & $\mathrm{X}$ & \\
\hline & Solanum cf. bullatum Vell. & & & $\mathrm{X}$ & \\
\hline Styracaceae & Styrax leprosus Hook \& Arn. & & $\mathrm{X}$ & & \\
\hline \multirow[t]{3}{*}{ Symplocaceae } & Symplocos celastrinea Mart. & & & $\mathrm{X}$ & rtp 202 \\
\hline & Symplocos falcata Brand & & $\mathrm{X}$ & $\mathrm{X}$ & rpms 11 \\
\hline & Symplocos sp. & & & $\mathrm{X}$ & \\
\hline Vochysiaceae & Callisthene fasciculata Mart. & & $\mathrm{X}$ & & \\
\hline Winteraceae & Drimys brasiliensis Miers & casca- d'anta & $\mathrm{X}$ & $\mathrm{X}$ & rpms 08 \\
\hline Total & & & 56 & 53 & \\
\hline
\end{tabular}

Jordão, apresentam tendência de decréscimo de riqueza com o aumento da altitude (Gentry 1988, Jarenkow \& Baptista 1987). Meliaceae e Sapindaceae, assim como Cyatheaceae e Rubiaceae, foram registradas somente no componente regenerante, ou seja, não tinham indivíduos adultos na parcela, portanto os juvenis resultaram de sementes provenientes de locais no entorno.

A riqueza e diversidade total obtida em um hectare em Campos do Jordão foi baixa (58 espécies e $\left.\mathrm{H}^{\prime}=3,08\right)$, comparada a outro inventário no interior da mesma unidade de conservação, no qual foram registradas 120 espécies em seis áreas descontínuas de 0,25 ha cada (Los 2004), refletindo a diversidade beta $\left(\mathrm{H}^{\prime}=3,43\right.$, tabela 5). Em sua área core de ocorrência, a maior diversidade encontrada para a Floresta Ombrófila Mista com árvores com pelo menos $5 \mathrm{~cm}$ de diâmetro foi registrada em Curitiba/PR $\left(\mathrm{H}^{\prime}=3,43 \mathrm{em}\right.$ Rondon Neto et al. 2002a) e a menor em Pinhais/PR $\left(H^{\prime}=2,18\right.$ por Seger et al. 2005) em área com indícios de exploração madeireira. Estudos que consideraram critério de inclusão menor obtiveram índices de diversidade mais elevados $\left(\mathrm{H}^{\prime}=3,65 \mathrm{em}\right.$ Kozera et al. 2005a e H' = 3,67 em Reginato \& Goldemberg 2007), o que evidencia a contribuição do subosque das florestas com araucária para a conservação da biodiversidade dessa formação. Quando adotado critério de inclusão mais restritivo (10 $\mathrm{cm}$ de DAP), os índices de diversidade variaram entre 2,83 (Sonego et al. 2007) e 3,51 (Durigan 1999), com a heterogeneidade atribuída ao histórico de uso da área, sendo comum a exploração madeireira de árvores do dossel ou o bosqueamento das áreas para cultivo de erva-mate. Além de diferentes critérios de inclusão, os índices de diversidade dos estudos mencionados foram obtidos com variações no desenho e esforço amostral (tabela 5), portanto devem ser avaliados com ressalvas.

Neste estudo, os componentes regenerante e adulto apresentaram flora muito semelhante e com os mesmos níveis de riqueza, embora tenham sido encontradas famílias exclusivas em ambos. As diferenças na composição de espécies em cada estrato podem estar relacionadas à exclusão competitiva e ao aumento da complexidade estrutural da vegetação, algo esperado em comunidade relativamente estável ou madura, 
portanto em equilíbrio dinâmico (Mueller-Donbois \& Ellemberg 1974).

Comparada ao componente regenerante, a diversidade de espécies para o componente adulto foi menor, mas não em função da riqueza e sim devido à menor equabilidade. Conclui-se que, na ausência de distúrbios severos, o estoque atual de jovens no componente regenerante permitirá a substituição de indivíduos nos estratos superiores, mantendo a composição e a diversidade em patamares similares aos encontrados atualmente.

O perfilhamento também foi mais comum para os indivíduos que não ocupam o dossel, como já observado por Gomes (1992) e Ivanauskas et al. (2000). Inúmeros fatores podem influenciar o perfilhamento, tais como fertilidade e textura solo, luz e temperatura, umidade, fase sucessional, competição e densidade (Abrahnson 1980). A ocorrência de geadas,
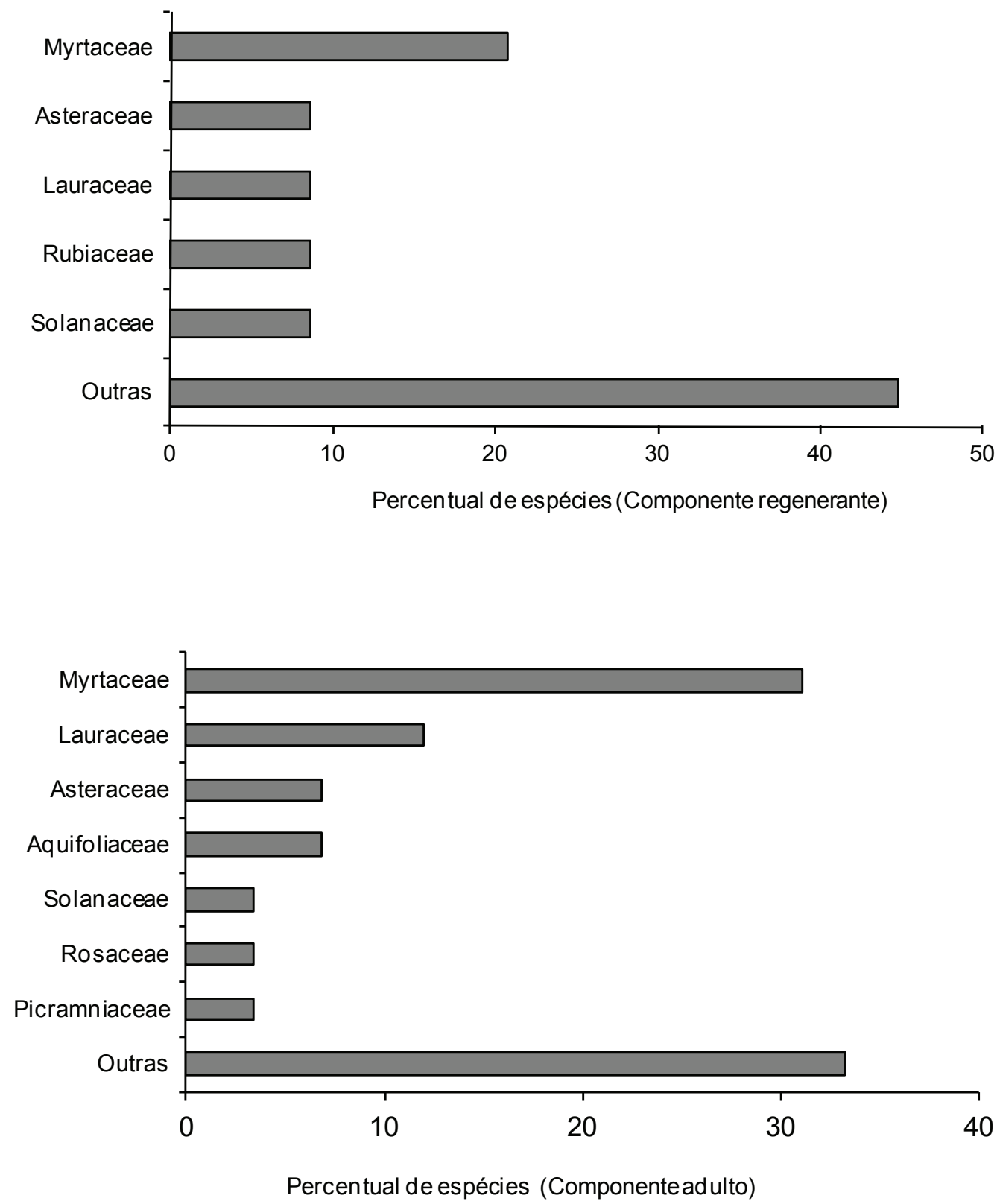

b

Figura 3. Famílias com maior número de espécies em trecho de Floresta Ombrófila Mista no Parque Estadual de Campos do Jordão, Campos do Jordão, SP, Brasil.

Figure 3. Families with higher number of species sampled in a stand of Mixed Ombrophilous Forest, Parque Estadual de Campos do Jordão, Campos do Jordão, São Paulo State, Brazil. 
Tabela 3. Parâmetros fitossociológicos das espécies arbustivo-arbóreas amostradas em trecho de Floresta Ombrófila Mista no Parque Estadual de Campos do Jordão, Campos do Jordão, SP, Brasil. $\mathrm{N}$ ha ${ }^{-1}$ : número de indivíduos por hectare; DR: Densidade relativa (\%); FR: Frequência relativa (\%); DoR: Dominância relativa (\%); VC: Valor de cobertura; VI: valor de importância.

Table 3. Phytossociological parameters of the sampled tree species in a stand of Mixed Ombrophilous Forest, at Parque Estadual de Campos do Jordão, Campos do Jordão, São Paulo State, Brazil. N ha ${ }^{-1}$ : number of individuals per hectare; DR: relative density (\%); FR: relative frequency (\%); DoR: relative dominance (\%); VC: coverage value; VI: importance value.

\begin{tabular}{|c|c|c|c|c|c|c|c|c|c|c|}
\hline \multirow{2}{*}{ Nome Científico } & \multicolumn{6}{|c|}{ Componente adulto } & \multicolumn{4}{|c|}{ Componente regenerante } \\
\hline & $\mathrm{N}_{\mathrm{ha}}{ }^{-1}$ & DR & FR & DoR & $\mathrm{VC}$ & VI & $\mathrm{N} \mathrm{ha}^{-1}$ & DR & FR & VI \\
\hline Podocarpus lambertii & 53,0 & 3,0 & 4,2 & 33,1 & 36,1 & 40,4 & 40 & 0,2 & 0,3 & 0,4 \\
\hline Myrceugenia miersiana & 400,0 & 22,6 & 6,5 & 8,7 & 31,3 & 37,8 & 1.520 & 6,6 & 5,3 & 11,9 \\
\hline Auraucaria angustifolia & 79,0 & 4,5 & 5,5 & 24,0 & 28,4 & 33,9 & 80 & 0,4 & 0,5 & 0,9 \\
\hline Drimys brasiliensis & 172,0 & 9,7 & 5,6 & 2,9 & 12,6 & 18,2 & 880 & 3,8 & 3,4 & 7,3 \\
\hline Myrcia hartwegiana & 165,0 & 9,3 & 5,5 & 1,6 & 11,0 & 16,5 & 1.400 & 6,1 & 5,8 & 11,9 \\
\hline Cinnamomum sellowianum & 92,0 & 5,2 & 5,4 & 4,5 & 9,7 & 15,1 & 1.120 & 4,9 & 4,8 & 9,6 \\
\hline Myrsine umbellata & 86,0 & 4,9 & 5,6 & 4,3 & 9,2 & 14,8 & 1.640 & 7,1 & 7,1 & 14,3 \\
\hline Prunus myrtifolia & 93,0 & 5,3 & 5,5 & 2,9 & 8,1 & 13,6 & 1.160 & 5,0 & 4,2 & 9,3 \\
\hline Annona rugulosa & 78,0 & 4,4 & 4,1 & 1,4 & 5,8 & 9,9 & 200 & 0,9 & 1,3 & 2,2 \\
\hline Symplocos falcata & 58,0 & 3,3 & 4,7 & 0,7 & 4,0 & 8,6 & 1.720 & 7,5 & 5,8 & 13,3 \\
\hline Myrcia laruotteana & 62,0 & 3,5 & 3,1 & 1,6 & 5,1 & 8,2 & 240 & 1,0 & 1,1 & 2,1 \\
\hline Ocotea sp. & 44,0 & 2,5 & 3,2 & 1,2 & 3,6 & 6,9 & & & & \\
\hline Ocotea dispersa & 34,0 & 1,9 & 3,0 & 0,6 & 2,5 & 5,5 & & & & \\
\hline Jacaranda puberula & 33,0 & 1,9 & 2,4 & 0,9 & 2,7 & 5,1 & 200 & 0,9 & 1,3 & 2,2 \\
\hline Myrceugenia sp. 1 & 25,0 & 1,4 & 2,4 & 0,8 & 2,2 & 4,6 & & & & \\
\hline Myrceugenia sp. 2 & 22,0 & 1,2 & 2,4 & 0,6 & 1,8 & 4,2 & & & & \\
\hline Ilex microdonta & 21,0 & 1,2 & 2,1 & 0,7 & 1,9 & 4,0 & 280 & 1,2 & 1,6 & 2,8 \\
\hline Picramnia parvifolia & 23,0 & 1,3 & 2,4 & 0,3 & 1,6 & 4,0 & 240 & 1,0 & 1,3 & 2,4 \\
\hline Myrcia venulosa & 17,0 & 1,0 & 1,8 & 0,9 & 1,9 & 3,7 & & & & \\
\hline Dicksonia sellowiana & 17,0 & 1,0 & 1,8 & 0,9 & 1,9 & 3,7 & 280 & 1,2 & 1,9 & 3,1 \\
\hline Dasyphyllum spinescens & 11,0 & 0,6 & 1,3 & 1,8 & 2,4 & 3,7 & 80 & 0,4 & 0,5 & 0,9 \\
\hline Piptocarpha regnellii & 15,0 & 0,9 & 1,7 & 0,6 & 1,4 & 3,1 & & & & \\
\hline Ilex taubertiana & 15,0 & 0,9 & 1,7 & 0,3 & 1,2 & 2,9 & 120 & 0,5 & 0,5 & 1,1 \\
\hline Siphoneugena reitzii & 12,0 & 0,7 & 1,6 & 0,1 & 0,8 & 2,3 & 360 & 1,6 & 1,9 & 3,4 \\
\hline Myrciaria tenella & 13,0 & 0,7 & 1,1 & 0,1 & 0,8 & 1,9 & & & & \\
\hline Myrsine ferruginea & 8,0 & 0,5 & 1,0 & 0,4 & 0,9 & 1,9 & & & & \\
\hline Clethra scabra & 8,0 & 0,5 & 1,0 & 0,1 & 0,6 & 1,6 & & & & \\
\hline Solanum pseudoquina & 3,0 & 0,2 & 0,4 & 0,9 & 1,0 & 1,5 & 160 & 0,7 & 0,8 & 1,5 \\
\hline Ilex pseudobuxus & 9,0 & 0,5 & 0,7 & 0,2 & 0,7 & 1,4 & & & & \\
\hline Ocotea puberula & 6,0 & 0,3 & 0,9 & 0,1 & 0,5 & 1,3 & 40 & 0,2 & 0,3 & 0,4 \\
\hline Myrceugenia ovata & 7,0 & 0,4 & 0,9 & 0,1 & 0,5 & 1,3 & 680 & 3,0 & 3,4 & 6,4 \\
\hline Styrax leprosus & 6,0 & 0,3 & 0,9 & 0,1 & 0,4 & 1,2 & & & & \\
\hline Ocotea bicolor & 7,0 & 0,4 & 0,7 & 0,1 & 0,5 & 1,2 & & & & \\
\hline Ilex theezans & 6,0 & 0,3 & 0,7 & 0,1 & 0,4 & 1,2 & & & & \\
\hline Vernonanthura discolor & 4,0 & 0,2 & 0,6 & 0,1 & 0,4 & 0,9 & & & & \\
\hline Myrceugenia brevipedicellata & 4,0 & 0,2 & 0,6 & 0,1 & 0,3 & 0,9 & & & & \\
\hline Rhamnus sphaerosperma & 5,0 & 0,3 & 0,4 & 0,1 & 0,3 & 0,8 & 240 & 1,0 & 1,1 & 2,1 \\
\hline
\end{tabular}


Souza et al.: Estrutura de trecho da Floresta Ombrófila Mista, SP, Brasil 399

Tabela 3 (continuação)

\begin{tabular}{|c|c|c|c|c|c|c|c|c|c|c|}
\hline \multirow{2}{*}{ Nome Científico } & \multicolumn{6}{|c|}{ Componente adulto } & \multicolumn{4}{|c|}{ Componente regenerante } \\
\hline & $\mathrm{N} \mathrm{ha}^{-1}$ & DR & FR & DoR & $\mathrm{VC}$ & $\overline{\mathrm{VI}}$ & $\mathrm{N} \mathrm{ha}^{-1}$ & $\mathrm{DR}$ & FR & VI \\
\hline Myrcia rostrata & 3,0 & 0,2 & 0,4 & 0,0 & 0,2 & 0,6 & & & & \\
\hline Zanthoxylum rhoifolium & 2,0 & 0,1 & 0,3 & 0,2 & 0,3 & 0,6 & 120 & 0,5 & 0,8 & 1,3 \\
\hline Mimosa scabrela & 2,0 & 0,1 & 0,3 & 0,2 & 0,3 & 0,6 & & & & \\
\hline Piptocarpha macropoda & 3,0 & 0,2 & 0,3 & 0,1 & 0,3 & 0,6 & & & & \\
\hline Picramnia glazioviana & 2,0 & 0,1 & 0,3 & 0,0 & 0,2 & 0,4 & & & & \\
\hline Eugenia ligustrina & 2,0 & 0,1 & 0,3 & 0,0 & 0,1 & 0,4 & 40 & 0,2 & 0,3 & 0,4 \\
\hline Myrceugenia myrcioides & 2,0 & 0,1 & 0,3 & 0,0 & 0,1 & 0,4 & & & & \\
\hline Ocotea glaziovii & 2,0 & 0,1 & 0,3 & 0,0 & 0,1 & 0,4 & & & & \\
\hline Maytenus salicifolia & 2,0 & 0,1 & 0,3 & 0,0 & 0,1 & 0,4 & & & & \\
\hline Baccharis oreophila & 1,0 & 0,1 & 0,1 & 0,0 & 0,1 & 0,2 & & & & \\
\hline Aegiphila integrifolia & 1,0 & 0,1 & 0,1 & 0,0 & 0,1 & 0,2 & & & & \\
\hline Casearia decandra & 1,0 & 0,1 & 0,1 & 0,0 & 0,1 & 0,2 & 80 & 0,4 & 0,5 & 0,9 \\
\hline Citronellla megaphylla & 1,0 & 0,1 & 0,1 & 0,0 & 0,1 & 0,2 & & & & \\
\hline Myrcia oligantha & 1,0 & 0,1 & 0,1 & 0,0 & 0,1 & 0,2 & 40 & 0,2 & 0,3 & 0,4 \\
\hline Solanum mauritianum & 1,0 & 0,1 & 0,1 & 0,0 & 0,1 & 0,2 & & & & \\
\hline Callisthene fasciculata & 1,0 & 0,1 & 0,1 & 0,0 & 0,1 & 0,2 & & & & \\
\hline Endlicheria paniculata & & & & & & & 1.200 & 5,2 & 6,6 & 11,8 \\
\hline Symplocos celastrinea & & & & & & & 1.440 & 6,3 & 5,0 & 11,3 \\
\hline Rudgea parquioides & & & & & & & 880 & 3,8 & 3,7 & 7,5 \\
\hline Capsicum flexuosum & & & & & & & 440 & 1,9 & 2,4 & 4,3 \\
\hline Solanum swartzianum & & & & & & & 360 & 1,6 & 1,3 & 2,9 \\
\hline Myrceugenia sp. 1 & & & & & & & 240 & 1,0 & 1,3 & 2,4 \\
\hline Cyathea atrovirens & & & & & & & 200 & 0,9 & 1,3 & 2,2 \\
\hline Myrciaria floribunda & & & & & & & 240 & 1,0 & 1,1 & 2,1 \\
\hline Asteraceae & & & & & & & 360 & 1,6 & 0,5 & 2,1 \\
\hline Cupania oblongifolia & & & & & & & 160 & 0,7 & 1,1 & 1,8 \\
\hline Ilex sp. & & & & & & & 200 & 0,9 & 0,8 & 1,7 \\
\hline Myrsine gardneriana & & & & & & & 120 & 0,5 & 0,8 & 1,3 \\
\hline Cabralea canjerana & & & & & & & 120 & 0,5 & 0,8 & 1,3 \\
\hline Vernonanthura sp. & & & & & & & 80 & 0,4 & 0,5 & 0,9 \\
\hline Symplocos sp. & & & & & & & 80 & 0,4 & 0,5 & 0,9 \\
\hline Porcelia macrocarpa & & & & & & & 80 & 0,4 & 0,5 & 0,9 \\
\hline Piptocarpha axilaris & & & & & & & 80 & 0,4 & 0,5 & 0,9 \\
\hline Guatteria australis & & & & & & & 80 & 0,4 & 0,5 & 0,9 \\
\hline Baccharis sp. & & & & & & & 80 & 0,4 & 0,3 & 0,6 \\
\hline Solanum cf. bullatum & & & & & & & 40 & 0,2 & 0,3 & 0,4 \\
\hline Solanum argenteum Dunal & & & & & & & 40 & 0,2 & 0,3 & 0,4 \\
\hline Rudgea jasminoides & & & & & & & 40 & 0,2 & 0,3 & 0,4 \\
\hline Myrsine vilosissima & & & & & & & 40 & 0,2 & 0,3 & 0,4 \\
\hline Psychotria longipes & & & & & & & 40 & 0,2 & 0,3 & 0,4 \\
\hline Myrtaceae & & & & & & & 40 & 0,2 & 0,3 & 0,4 \\
\hline Ilex dumosa & & & & & & & 40 & 0,2 & 0,3 & 0,4 \\
\hline
\end{tabular}


comuns no inverno de Campos do Jordão, pode estar relacionada à morte de gemas apicais com aumento de perfilhamento. Essas mudanças ambientais, mesmo em pequena escala, podem provocar alterações estruturais no estrato inferior, pois as espécies desse componente respondem mais rapidamente a essas mudanças do que aquelas do estrato superior (Gentry \& Dodson 1987).

Em linhas gerais, em ambiente onde a competição por espaço seja muito intensa, a expansão lateral dos indivíduos e a reprodução vegetativa são estratégias vantajosas, uma vez que as plântulas originadas por semente têm poucas possibilidades de se estabelecer e competir (Gomes 1992, Martins et al. 2009). Soma-se a isso o fato de que araucárias são árvores emergentes com grande contribuição para a formação de serapilheira da floresta, por meio da eliminação de cascas do tronco, de galhos durante o desenvolvimento de sua copa corimbiforme e de sementes no período reprodutivo, popularmente conhecidas como pinhões.
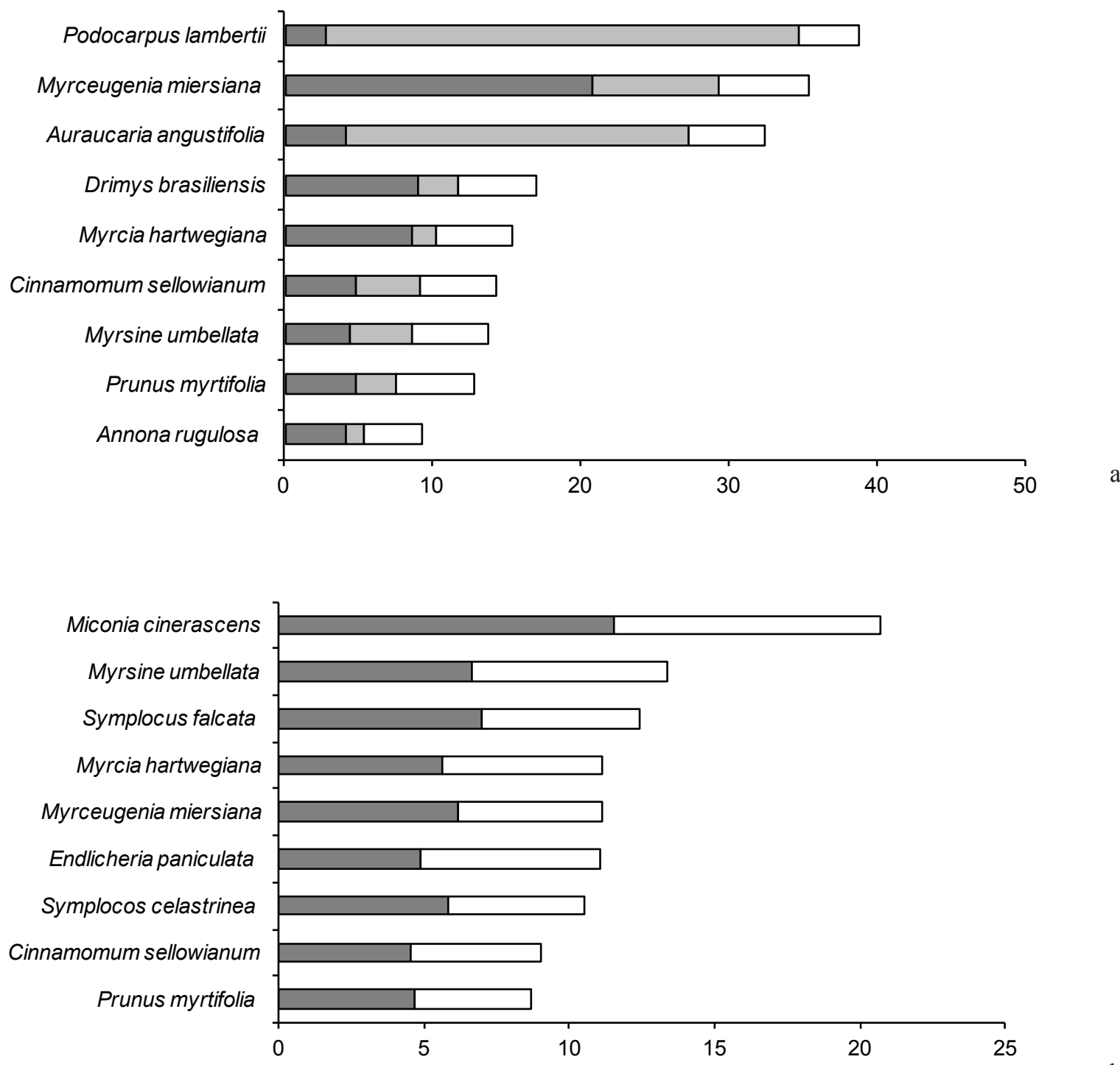

Figura 4. Espécies de maior valor de importância no trecho de Floresta Ombrófila Mista no Parque Estadual de Campos do Jordão,

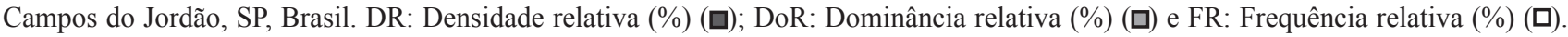
a. Componente adulto, b. Componente regenerante.

Figure 4. Species with the greatest importance value sampled in a stand of Mixed Ombrophilous Forest, Parque Estadual de Campos

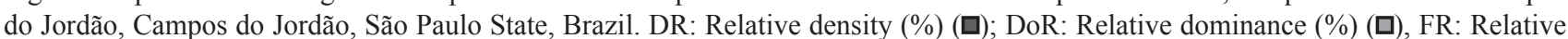
frequency component (\%) (ם). a. Adult component; b. Sapling component. 
Tabela 4. Parâmetros da comunidade arbórea de um trecho de Floresta Ombrófila Mista no Parque Estadual de Campos do Jordão, Campos do Jordão, SP, Brasil.

Table 4. Tree community parameters in a stand of Mixed Ombrophilous Forest, at Parque Estadual de Campos do Jordão, Campos do Jordão, São Paulo State, Brazil.

\begin{tabular}{lccc}
\hline \multirow{2}{*}{ Componente } & \multicolumn{3}{c}{ Riqueza $\left(\mathrm{n}^{\circ}\right.$ de espécies $)$} \\
\cline { 2 - 4 } & Observada & \multicolumn{2}{c}{ Esperada } \\
\cline { 2 - 4 } Adulto & 56 & $58,9-64,0$ & $61,3-64,8$ \\
Regenerante & 53 & $56,7-67,6$ & $58,4-63,5$ \\
\hline
\end{tabular}

A queda de galhos e de cones grandes e pesados produz pequenos e frequentes distúrbios no subosque, com danos aos indivíduos jovens, inclusive de regenerantes da própria Araucaria angustifolia (Valente et al. 2010). Todos esses fatores podem ter contribuído para o destaque em valor de importância para as espécies de Myrtaceae que, entre outras vantagens adaptativas, apresentam elevada densidade devido aos muitos indivíduos perfilhados no subosque. Além da elevada riqueza de espécies, Myrtaceae também apresentou populações densas no componente regenerante, portanto com a formação de grandes estoques de juvenis com maior probabilidade de atingir a fase adulta.

Outros descritores importantes para análise da comunidade são os valores de densidade e área basal total. Jarenkow \& Budke (2009) sintetizaram dados de 16 estudos em Floresta Ombrófila Mista, com delineamentos amostrais muito variáveis, mas que geralmente empregaram o método de parcelas com área entre 0,18 e 8,7 ha e critério de inclusão a partir de cinco centímetros de diâmetro a 1,30 m de altura do solo. Para esses trechos florestais, a densidade total variou entre 455 a 1.972 ind ha $^{-1}$, mas muitos se situaram entre 700 e 900 ind ha $^{-1}$. A área basal variou de $17,63 \mathrm{~m}^{2} \mathrm{ha}^{-1} \mathrm{em}$ áreas com vegetação alterada a até $50,83 \mathrm{~m}^{2} \mathrm{ha}^{-1} \mathrm{em}$ estandes bem conservados. Com esses valores como referência, pode-se afirmar que a floresta avaliada em Campos do Jordão encontra-se nos padrões esperados para uma floresta madura, com densidade de 1.921 ind ha $^{-1} \mathrm{e}$ área basal total de $53,60 \mathrm{~m}^{2} \mathrm{ha}^{-1}$ para o componente adulto.

Com relação à ocupação do espaço vertical, poucos trabalhos apresentam análises da estratificação da Floresta Ombrófila Mista, mas os que o fizeram relatam a presença de Araucaria angustifolia entre as árvores emergentes, com indivíduos entre 24 e $38 \mathrm{~m}$ de altura (Fonseca et al. 2009). Em Campos do Jordão, além da Araucaria angustifolia e Podocarpus lambertii também se destacou entre as emergentes. Essas duas espécies podem ser consideradas marcadoras da fisionomia de Floresta Ombrófila Mista de Campos do Jordão, com indivíduos superiores a $20 \mathrm{~m}$ de altura. Outra população que merece destaque devido à sua importância para a conservação é a composta por indivíduos de Dicksonia sellowiana, samambaia arborescente conhecida popularmente por "xaxim" e típica de subosque da Floresta Ombrófila Mista. A espécie encontra-se ameaçada devido à exploração econômica no passado para fins de ornamentação e paisagismo (Windisch 2002). O desaparecimento de plantas adultas compromete a preservação da espécie em si, descaracteriza a Floresta Ombrófila Mista e diminui a disponibilidade de microhabitats para várias espécies epifíticas (Fraga \& Schmitt 2008). Também em Campos do Jordão foi registrada a presença de Siphoneugena reitzii, árvore de 8 a $10 \mathrm{~m}$ de altura, típica de Florestas nebulares e Ombrófilas Mistas (Legrand \& Klein 1977), classificada como vulnerável à extinção para o Estado de São Paulo. A presença dessas duas espécies na área de estudo revela a importância da área protegida para a conservação in situ das populações dessas espécies ameaçadas.

Relativamente comum em florestas na Serra da Mantiqueira, Podocarpus lambertii acompanha a área de ocorrência da Floresta Ombrófila Mista nos Estados do Paraná, Santa Catarina e Rio Grande do Sul (Ragagnin et al. 1994, Kozera et al. 2005a). Foi citado como espécie comum do estrato inferior de florestas do Rio Grande do Sul (Maixner \& Ferreira 1976) ou em agrupamentos quase puros nos capões das áreas campestres do Paraná (Klein \& Hatschbach 1962). Já em um mesmo fragmento de Floresta Ombrófila Mista é possível encontrar indivíduos de Podocarpus lambertii com diferentes idades e em ambientes sucessionais distintos, desde trechos em processo de regeneração natural até porções mais maduras da floresta (Backes 1973). Isto ocorre porque Podocarpus lambertii é uma espécie plástica que se adapta a diferentes condições lumínicas e que tem seu desenvolvimento em altura aumentado em ambientes mais sombreados, a fim de alcançar a luz com maior facilidade (Chiamolera et al. 2010). Desse modo, em florestas maduras o pinheirinho-bravo atinge porte elevado, como registrado no levantamento fitossociológico de trecho de Floresta Ombrófila Mista em Curitiba (Kozera et al. 2006 b), onde ocupou a primeira posição em valor de importância, assim como em Campos do Jordão. 
Embora Podocarpus lambertii e Araucaria angustifolia tenham se destacado em valor de importância na comunidade em função da elevada dominância, a densidade de indivíduos dessas populações de coníferas no componente regenerante foi muito inferior aos valores registrados para grande parte das latifoliadas, o que pode comprometer a manutenção de populações viáveis dessas espécies a longo prazo. Essas variações sugerem mudanças futuras de dominância para o trecho avaliado, como já observado na Reserva Genética de Caçador/SC, onde Araucaria angustifolia não apresentou indivíduos regenerantes (Caldato et al. 1996). Em Garapuava/PR, a densidade de Araucaria angustifolia na regeneração natural foi pouco expressiva e atribuída principalmente à predação dos pinhões (Cordeiro \& Rodrigues 2007). Na Floresta Nacional de São Francisco de Paula/RS, a Araucaria angustifolia também apresentou número reduzido de indivíduos nas categorias plântula e juvenil (Navares et al. 2010).

A estratégia predominante em coníferas do hemisfério sul caracteriza-se pelo recrutamento intermitente resultante de distúrbio ocasional (Kershaw \& Wagstaff 2001). Esses distúrbios são necessários porque alteram o regime de luz, assim, o sombreamento gerado pelas espécies latifoliadas dos estratos superiores estaria relacionado ao fracasso regenerativo da araucária, considerada heliófita (Reitz \& Klein 1966). Em ambientes florestais, nem mesmo clareiras podem garantir o desenvolvimento de plântulas e juvenis, pois as espécies latifoliadas normalmente ocupam e sombreiam mais rapidamente esses espaços, comprometendo o sucesso de regeneração da Araucaria angustifolia (Klein 1960, Rambo 1994).

No entanto, Duarte et al. (2002) afirmaram que a Araucaria angustifolia é capaz de tolerar sombreamento, germinar e se estabelecer em baixas condições de luz, portanto não é estritamente heliófila e pioneira, sendo capaz de se estabelecer no subosque da floresta. Essa constatação foi corroborada por Silva et al. (2010), ao afirmarem que muitas sementes de Araucaria angustifolia germinam a cada ano,

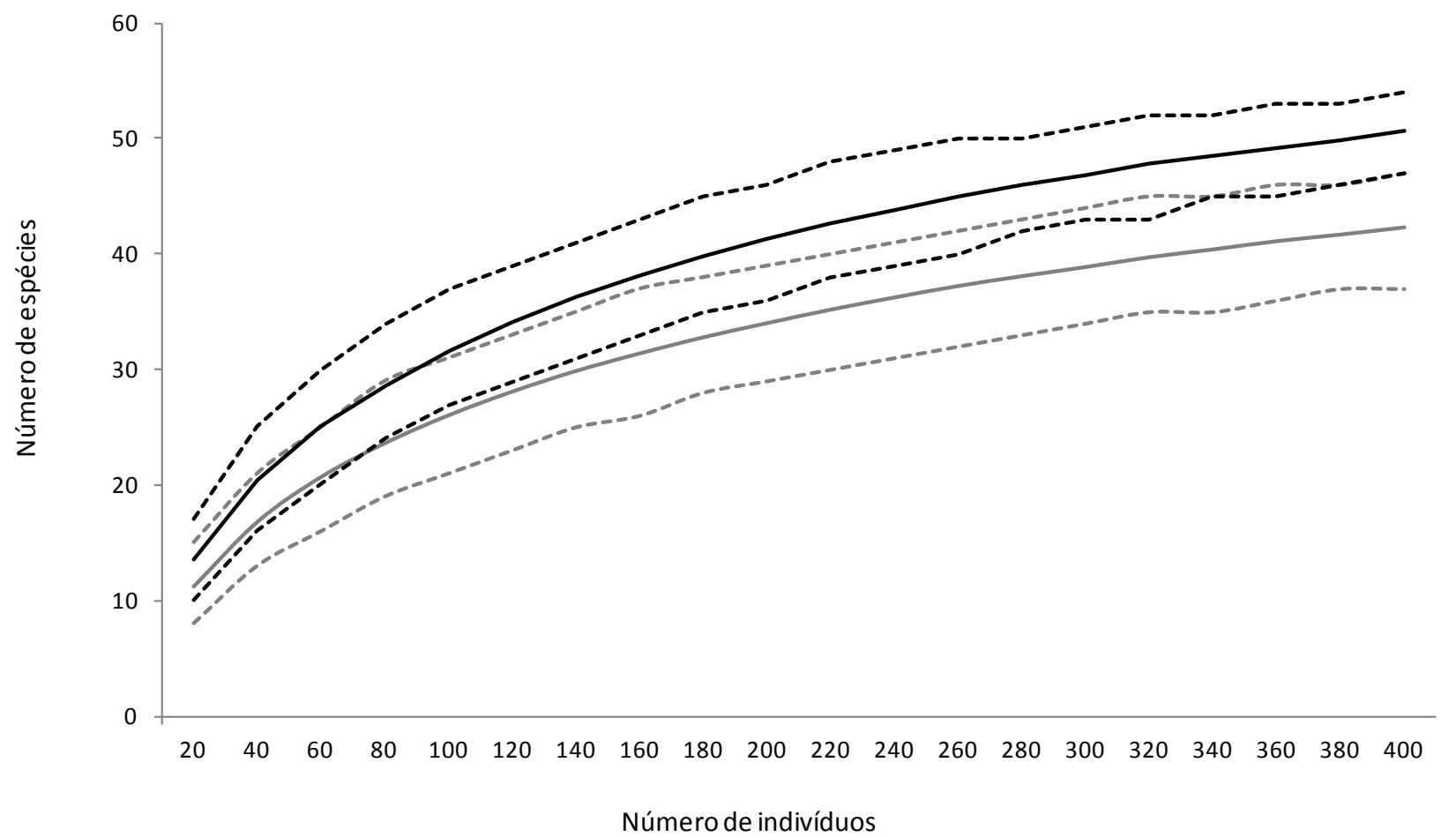

Figura 5. Curva de acumulação de espécies (linhas cheias), média e intervalo de confiança (linhas tracejadas) de 95\% para amostragem em trecho de Floresta Ombrófila Mista no Parque Estadual de Campos do Jordão, Campos do Jordão, SP, Brasil. Componente Adulto (-), Componente Regenerante (-).

Figure 5. Species accumulation curve (continuous lines), mean and $95 \%$ confidence interval (dashed lines) for the samples taken in a stand of Mixed Ombrophilous Forest, at Parque Estadual de Campos do Jordão, Campos do Jordão, São Paulo State, Brazil. Adult Component $(-)$, Regenerating component (-) 
em ambientes com as mais variadas condições de luminosidade, e que as plântulas se estabelecem com facilidade devido a grande quantidade de reserva de suas sementes. No entanto, o filtro ecológico ocorre à medida que se esgotam as reservas, quando a plântula se torna dependente dos processos de síntese e começa a apresentar dificuldades de crescimento e desenvolvimento em ambientes florestais ombrófilos: de acordo com os autores, muitas plântulas morrem antes de completarem um ano, tendo atingido menos de $50 \mathrm{~cm}$ de altura (Backes 1973, 2001).

Outro fator que pode dificultar a conservação dos relictos de Floresta Ombrófila Mista na Serra da Mantiqueira são as mudanças climáticas. Araucaria angustifolia e Podocarpus lambertii, assim como outros elementos de florestas temperadas, podem estar desfavorecidas no componente de regeneração devido à incompatibilidade com o clima atual (Klein 1960). A Floresta Ombrófila Mista é considerada uma das mais sensíveis a variações climáticas e as coníferas ali presentes são frequentemente utilizadas como indicadoras de paleoclimas (Siqueira 2006). Ao permanecer o clima quente/úmido do atual período interglacial, mesmo esses refúgios podem não ser suficientes para a conservação das espécies, pois as coníferas podem ser eliminadas pela concorrência de grupos florísticos próprios de climas ombrotérmicos (Leite 1994).

Nesse contexto, pode-se afirmar que a Floresta Ombrófila Mista na região de Campos do Jordão não é uma comunidade fechada (Ricklefs \& Müller 1999), nas quais as espécies se encontram fortemente relacionadas (associadas) e com limites de distribuição coincidentes. A baixa densidade de coníferas no estrato regenerante e a possível extinção local frente às mudanças climáticas condizem com a teoria proposta por Gleason (1926), em que cada espécie tem distribuição independente das demais e, dessa forma, não apresentam limites naturais; seus limites são arbitrários em relação às distribuições geográficas e ecológicas de suas espécies componentes que, independentemente, podem fazer parte de diferentes "associações". Teorias contemporâneas relacionadas à sucessão e conservação de ecossistemas naturais assumem que esses são sistemas abertos, sujeitos à migração e imigração de espécies (Lortie et al. 2004). Distúrbios são frequentes e comuns, alterando a composição e as interações entre espécies e a

Tabela 5. Levantamentos florísticos e fitossociológicos utilizados na comparação florística entre áreas de Floresta Ombrófila Mista. P: levantamento fitossociológico em parcelas; Q: levantamento fitossociológico por quadrantes; DAP: diâmetro a 1,30 de altura do solo; H': Índice de Shannon; S: Número de espécies.

Table 5. Floristics and phytosociological surveys used in the floristic comparison among Mixed Ombrophilous Forest areas. P: phytosociological survey in the plots; Q: phytossociological survey in the quadrants; DAP: diameter at breast height (1.30 m); H': Shannon index; S: species number.

\begin{tabular}{llrlrrr}
\hline Autores & Localidade & $\begin{array}{r}\text { DAP } \\
(\mathrm{cm})\end{array}$ & $\begin{array}{c}\text { Levantamento } \\
\text { fitossociológico }\end{array}$ & $\begin{array}{r}\text { Parcelas (m) } \\
\text { Pontos }^{-1}\end{array}$ & $\mathrm{H}^{\prime}$ & $\mathrm{S}$ \\
\hline Este trabalho & Campos do Jordão, SP & 5,0 & $\mathrm{P}$ & $50(10 \times 20)$ & 3,08 & 58 \\
Los (2002) & Campos do Jordão, SP & 5,0 & $\mathrm{P}$ & $6 \times 10(10 \times 25)$ & 3,43 & 120 \\
Kozera et al. (2005) & Curitiba, PR & 3,3 & $\mathrm{Q}$ & 150 pontos & 3,57 & 77 \\
Rondon-Neto et al. (2002) & Curitiba, PR & 5,0 & $\mathrm{P}$ & $18(10 \times 20)$ & 3,43 & 77 \\
Watzlawick et al. (2005) & General Carneiro, PR & 10,0 & $\mathrm{P}$ & $20(12 \times 12)$ & 3,26 & 39 \\
Silva (2003) & Guarapuava, PR & & $\mathrm{Q}$ & 111 pontos & 3,36 & 55 \\
Silva (2003) & Guarapuava, PR & & $\mathrm{Q}$ & 111 pontos & 2,55 & 42 \\
Cordeiro \& Rodrigues (2007) & Guarapuava, PR & 5,0 & $\mathrm{P}$ & $32(10 \times 10)$ & 2,79 & 46 \\
Seger et al. (2005) & Pinhais, PR & 5,0 & $\mathrm{P}$ & $15(10 \times 100)$ & 2,18 & 41 \\
Reginato \& Goldenberg (2007) & Piraquara, PR & 3,2 & $\mathrm{P}$ & $1(120 \times 60)$ & 3,67 & 85 \\
Durigan (1999) & São João do Triunfo, PR & 10,0 & $\mathrm{P}$ & $4(100 \times 100)$ & 3,51 & 69 \\
Rondon Neto et al. (2002b) & Criúva, RS & 5,0 & $\mathrm{P}$ & $8(10 \times 100)$ & 2,76 & 37 \\
Nascimento et al. (2001) & Nova Prata, RS & 10,0 & $\mathrm{P}$ & $20(10 \times 50)$ & 3,00 & 55 \\
Sonego et al. (2007) & São Francisco de Paula, RS & 5,0 & $\mathrm{P}$ & $29(10 \times 10)$ & 2,95 & 41 \\
Sonego et al. (2007) & São Francisco de Paula, RS & 10,0 & $\mathrm{P}$ & $29(10 \times 10)$ & 2,83 & 35 \\
\hline
\end{tabular}


disponibilidade de recursos. Portanto, o equilíbrio dinâmico do ecossistema é influenciado pelo regime de distúrbios ao qual tem sido submetido e se adaptado. Como resultado, as paisagens são consideradas mosaicos dinâmicos de unidades ou manchas definidas por estádios de sucessão e variações ambientais (Martins et al. 2009).

Em Campos do Jordão, embora a Araucaria angustifolia e o Podocarpus lambertii estejam pobremente representados no componente regenerante da Floresta Ombrófila Mista, indivíduos dessas espécies são frequentes na borda da floresta e com expansão sobre o campo, o que revela o sucesso de ambas na ocupação de espaços abertos. Assim, mantidas as condições climáticas atuais, a perpetuação das populações dessas espécies na unidade de conservação está vinculada a ações de manejo que garantam a manutenção dos trechos florestais nos fundos de vale e dos campos naturais nos interflúvios, com as coníferas presentes nos ecótonos.

Portanto, mais uma vez se reconhece a influência antrópica nos ecossistemas, tanto como fonte de perturbação e degradação quanto como agente de manejo, visando à sua conservação e restauração (Martins et al. 2009). Caso nenhuma medida de manejo seja tomada, é provável que as coníferas sejam extintas localmente e que a vegetação passe então a não ser reconhecida como Floresta Ombrófila Mista, mas sim como Floresta Ombrófila Densa, já que as coníferas não mais se destacariam na fisionomia florestal. Esta predição corresponde à descrição de Klein (1960) para florestas compostas predominantemente por espécies características da Floresta Ombrófila Densa, ocorrendo esporadicamente manchas de pinheiros, em sua maioria constituída por indivíduos velhos, adultos ou raquíticos.

\section{Agradecimentos}

Os autores agradecem aos especialistas Geraldo A.D.C. Franco (generalista) e aos especialistas das famílias Myrtaceae (Osny Aguiar, Marcos Sobral e Fiorella Mazine) e Lauraceae (João Batista Baitello); à FAPESP que, através do Programa BIOTA, proporcionou os recursos necessários para o desenvolvimento da pesquisa (processo 01/05146-6) e a bolsa de mestrado para a primeira autora (processo 06/54440-8).

\section{Literatura citada}

Ab' Sáber. A.N. 1992. A teoria dos refúgios: Origem e significado. Revista do Instituto florestal, Edição especial 4: 29-34.

Ab'Sáber, A.N. 1977. Os domínios morfoclimáticos na América do Sul. Geomorfologia. IGEOG-USP, São Paulo.

Abranson, W.G. 1980. Demography and vegetative reproduction . In: O.T. Solbrig (ed.). Demography and evolution in plant populations. University of California Press, Los Angeles, pp.89-106.

Aranha Filho, J.L.M. 2008. Flora da Serra do Cipó, Minas Gerais: Symplocaceae. Boletim de Botânica da Universidade de São Paulo 26: 69-77.

Arzolla, F.A.R.P. 2002. Florística e fitossociologia de trecho da Serra da Cantareira. Núcleo Águas Claras. Parque Estadual da Cantareira. Mairiporã , SP. Dissertação de Mestrado, Universidade Estadual de Campinas, Campinas, $82 \mathrm{p}$.

Backes, A. 1973. Contribuição ao conhecimento da ecologia da mata de Araucária. Tese de Doutorado, Universidade de São Paulo, São Paulo.

Backes, A. 2001. Determinação da idade e regeneração natural de uma população de Araucaria angustifolia em um povoamento florestal localizado no município de Caxias do Sul, RS, Brasil. Iheringia 56: 115-130.

Baitello. J.B., Aguiar. O.T., Rocha. F.T., Pastore. J.A. \& Esteves. R. 1992. Florística e fitossociologia do estrato arbóreo de um trecho da Serra da Cantareira (Núcleo Pinheirinho) - SP. Revista do Instituto Florestal 4: 291-298.

Barreta, D. 2007. Fauna do solo e outros atributos edáficos como indicadores da qualidade ambiental em áreas com Araucaria angustifolia no Estado de São Paulo. Tese de Doutorado, Universidade de São Paulo, Piracicaba.

Bergamin, R.S. \& Mondin, C.A. 2006. Composição florística e relações fitogeográficas do component arbóreo de um fragmento florestal no município de Barra do Ribeiro, Rio Grande do Sul, Brasil. Pesquisas Botânica 57: 217-230.

Caiafa, A.N. \& Martins, F.R. 2007. Taxonomic identification, sampling methods, and minimum size of the tree sampled: implications and perspectives for studies in the Brazilian Atlantic rainforest. Functional Ecosystems and Communities 1: 95-104.

Caldato, S.L., Floss, P.A., Croce, D.M. \& Longhi, S.J. 1996. Estudos da regeneração natural, banco de semente e chuva de sementes na Reserva Genética Florestal de Caçador, SC. Ciência Florestal 6: 27-38.

Cardoso, E.J.B.N. 2004. Biodiversidade vegetal e de organismos edáficos em ecossistemas de Araucaria angustifolia naturais e impactados no Estado de São Paulo. Projeto Temático e Relatório de Pesquisa. FAPESP, São Paulo. 
Chazdon, R.L., Colwell, R.K., Denslow, J.S. \& Guariguata, M.R. 1998. Statistical methods for estimating species richness of woody regeneration in primary and secondary rain forests of northeastern Costa Rica. In: R.L. Chazdon, R.K. Colwell, J.S. Denslow \& M.R. Guariguata (eds.). Forest biodiversity research, monitoring and modeling: conceptual background and old world case studies. Parthenon Publishing, Paris, pp. 285-309.

Chiamolera, L.B., Angelo, A.C. \& Boeger, M.R. 2010. Resposta morfoanatômica da folha de Podocarpus lambertii Klotzsch ex Endl (Podocarpaceae) implantado em duas áreas com diferentes graus de sucessão às margens do Reservatório Iraí - PR. Biotemas 23: 1-11.

Colwell, R.K. \& Coddington, J.A. 1994. Estimating terrestrial biodiversity through extrapolation. Philosophical Transactions of the Royal Society of London 345: 101-118.

Cordeiro, J. \& Rodrigues, W.A. 2007. Caracterização fitossociológica de um remanescente de Floresta Ombrófila Mista em Guarapuava, PR. Revista Árvore 31: 545-554.

Duarte, L.S., Dillenburg, L.R. \& Rosa, L.M. 2002. Assessing the role of light avaliability in the regeneration of Araucaria angustifolia (Araucaricaceae). Australian Journal of Botany 50: 741-751.

Durigan, M.E. 1999. Florística, dinâmica e análise protéica de uma Floresta Ombrófila Mista em São João do Triunfo - PR Curitiba. Dissertação de Mestrado, Universidade Federal do Paraná, Curitiba.

Efron, B. \& Tibshirani, R.J. 1993. An introduction to the bootstrap. Chapman \& Hall, New York.

Fonseca C.R., Souza A.F., Leal-Zanchet A.N. Dutra T., Backes A. \& Ganado G. 2009. Floresta com Araucária: ecologia, conservação e desenvolvimento sustentável. Editora Holos, Ribeirão Preto.

Fraga, L.L., da Silva, L.B. \& Schimitt, J.L. 2008. Composition and vertical distribution of epiphytic pteridophytes on Dicksonia sellowiana Hook. (Dicksoniaceae), in mixed ombrophylous forest in Southern Brazil. Biota Neotropica 8: 123-129.

Gentry, A.H. \& Dodson, C. 1987. Contribution of non trees to species richness of a tropical rain forest. Biotropica 19: 149-156.

Gentry, A.H. 1988. Changes in plant community diversity and floristic composition on environmental and geographical gradients. Annals of the Missouri Botanical Garden 75: 1-34.

Gleason, H.A. 1926. The individualistic concept of the plant association. Bulletin of the Torrey Botanical Club 53: 7-26.

Gomes, E.P.C. 1992. Fitossociologia do componente arbóreo de um trecho de mata em São Paulo, SP. Dissertação de Mestrado, Universidade de São Paulo, São Paulo.
Gotelli, N.J. \& Colwell, R.K. 2001. Quantifying biodiversity:procedures and pitfalls in the measurement and comparison of species richness. Ecology Letters 4: 379-391.

IBAMA. 2008. Listagem oficial das espécies vegetais brasileiras ameaçadas de extinção. http://www.ibama. gov.br (acesso em 20.03.2011).

Ivanauskas, N.M. \& Rodrigues R.R. 2000. Florística e fitossociologia de remanescentes de floresta estacional decidual em Piracicaba, São Paulo, Brasil. Revista Brasileira de Botânica 23: 291-304.

Ivanauskas, N.M. 2007. Floresta Ombrófila Mista: Avaliação da diversidade vegetal em florestas de araucária no Estado de São Paulo. Projeto de auxílio à pesquisa. CNPq, Brasília.

Jarenkow, J.A. \& Baptista, L.R.M. 1987. Composição florística e estrutura da Mata com Araucaria na Estação Ecológica de Aracuri, Esmeralda, RS. Napaea 3: 9-18.

Jarenkow, J.A. \& Budke, J.C. 2009. Padrões florísticos e análise estrutural de remanescentes de Florestas com Araucária no Brasil. In: C.R. Fonseca, A.F. Souza, A.N. Leal-Zanchet, T. Dutra, A. Backes \& G. Ganado (eds.). Floresta com Araucária: ecologia, conservação e desenvolvimento sustentável. Editora Holos, Ribeirão Preto, p. 113-126.

Jarenkow, J.A. 1985. Composição florística e estrutura da Mata com Araucária em Estação Ecológica Aracuri, Esmeralda, Rio Grande do Sul. Dissertação de Mestrado, Universidade Federal do Rio Grande do Sul, Porto Alegre.

Kershaw, P. \& Wagstaff, B. 2001. The southern conifer family Araucariaceae: History, status, and value for paleoenvironmental reconstruction. Annual Review of Ecology and Systematics 32: 397-414.

Klein, R.M. \& Hatschbach, G. 1962. Fitofisionomia e notas sobre a vegetação para acompanhar a planta fitogeográfica do município de Curitiba e arredores (Paraná). Boletim da Universidade do Paraná 4: 1-29.

Klein, R.M. 1960. O aspecto dinâmico do pinheiro brasileiro. Sellowia 12: 17-44.

Klein, R.M. 1984. Aspectos dinâmicos da vegetação do sul do Brasil. Sellowia 36: 5-54.

Kozera, C., Dittrich, V.A.O. \& Silva, S.M. 2006a. Composição florística da floresta ombrófila mista montana do parque municipal do Barigüi, Curitiba, PR. Revista Floresta 36: 45-58.

Kozera, C., Dittrich, V.A.O. \& Silva, S.M. 2006 b. Fitossociologia do componente arbóreo de um fragmento de Floresta Ombrófila Mista Montana, Curitiba, PR, BR. Revista Floresta 36: 225-237.

Kronka, F.J.N., Nalon, M.A., Matsukuma, C.K., Kanashiro, M.M., Pavão, M., Durigan, G., Lima, L.M.P.R., Guillaumon, J.R., Baitello, J.B. \& Borgo, S.C. 2005. Inventário Florestal da Vegetação Natural do Estado de São Paulo. Imprensa oficial, São Paulo. 
Legrand, C.D. \& Klein, R.M. 1977. Mirtáceas. In: R. Reitz (ed.). Flora Ilustrada Catarinense. Herbário Barbosa. Rodrigues, Itajaí, pp.572-730.

Leite, P.F. 1994. As diferentes unidades fitoecológicas da Região Sul do Brasil. Proposta de classificação. Dissertação de Mestrado, Universidade Federal do Paraná, Curitiba.

Lortie, C.J., Brooker, R.W., Choler, P., Kikvidze, Z., Michalet, R., Pugnaire, F.I. \& Callaway, R.M. 2004. Rethinking plant community theory. Oikos 107: 433-438.

Los, M.M. 2004. Florística, estrutura e diversidade de floresta com Araucaria em áreas de diferentes tamanhos. Dissertação de Mestrado, Universidade de São Paulo, São Paulo.

Magurran, A.E. 2004. Measuring Biological Diversity. Blackwell Publishing, Oxford.

Maixner, A.E. \& Ferreira, L.A.B. 1976. Contribuição ao estudo das essências florestais e frutíferas no Estado do Rio Grande do Sul. Trigo e Soja 18: 3-20.

Mantovani, W. 1993. Estrutura e dinâmica da Floresta Atlântica na Juréia. Iguape. SP. Tese de Livre-Docência, Universidade de São Paulo, São Paulo.

Martins. F.R. 1991. Estrutura de uma floresta mesófila. UNICAMP, Campinas.

Martins., S.V. 2009. Ecologia de florestas tropicais do Brasil. Editora UFV, Viçosa.

Medeiros, J.D., Savi, M. \& Brito, B.F.A. 2005. Seleção de áreas para criação de Unidades de Conservação na Floresta Ombrófila Mista. Biotemas 18: 33-50.

Meireles, L.D., Shepherd G.J. \& Kinoshita L.S. 2008. Variações na composição florística e na estrutura fitossociológica de uma floresta ombrófila densa alto-montana na Serra da Mantiqueira, Monte Verde, MG. Revista Brasileira de Botânica 31: 559-574.

Modenesi, M.C. 1988. Significado dos depósitos correlativos quaternários em Campos do Jordão - São Paulo: implicações paleoclimáticas e paleoecológicas. Instituto Geológico 7: 1-155.

Mori, S.A., Boom. B.M. \& Prance. G.T. 1981.Distribution patterns and conservation of eastern Brazilian coastal forest tree species. Brittonia 33: 233-245.

Mueller-Dombois, D. \& Ellenberg, H. 1974. Aims and methods of vegetation ecology. John Wiley \& Sons, New York.

Narvaes, I.S., Brena, D.A. \& Longhi, S.L. 2010. Estrutura da regeneração natural em Floresta Ombrófila Mista na Floresta Nacional de São Francisco de Paula, RS. Ciência Florestal 15: 331-342.

Nascimento, A.R.T., Longhi, S.J. \& Bena, D.A. 2001. Estrutura e padrões de distribuição espacial de espécies arbóreas em uma amostra de Floresta Ombrófila Mista Em Nova Prata, RS. Ciência Florestal 11: 105-119.
Nastri, V.D.F., Catharino, E.L.M., Rossi, L., Barbosa, L.M., Pirré, E., Beneditelli, C., Asperti, L.M., Dorta, R.O. \& Costa, M.P. 1992. Estudos fitossociológicos em uma área do Instituto de Botânica de São Paulo utilizada em programa de Educação ambiental. Revista do Instituto Florestal 4: 219-225.

Parker, G.G. \& Brown, M.J. 2000. Forest canopy stratification - Is it useful? American Naturalist 155: 473-484.

Pielou, E.C. 1966. Introduction to mathematical ecology. Wiley-Interscience, New York.

Polisel, R.T. 2011. Análise fitossociológica do subosque de florestas com araucária e sua relação fitogeográfica com outras formações florestais da Floresta Atlântica s.l. Dissertação de Mestrado, Universidade Estadual de Campinas, Campinas.

Ragagnin, L.I.M., Costa, E.C. \& Hoppe, J.M. 1994. Maturidade fisiológica de sementes de Podocarpus lambertii Klotzsch. Ciência Florestal 4: 23-41.

Rambo B. 1994. A Fisionomia do Rio Grande do Sul. Unisinos, São Leopoldo.

Reginato, M. \& Goldenberg, R. 2007. Análise florística, estrutural e fitogeográfica da vegetação em região de transição entre as Florestas Ombrófilas Mista e Densa Montana, Piraquara, Paraná, Brasil. Hoehnea 34: 349-364.

Reitz, R. \& Klein, R.M. 1966. Araucariáceas. Flora Ilustrada Catarinense. Itajaí.

Ricklefs, R.E. \& Miller, G.L. 1999. Ecology. W.H. Freeman, New York.

Robim, M.J. 1990. Flora arbórea, arbustiva e herbácea do Parque Estadual de Campos do Jordão, São Paulo. Revista do Instituto Florestal 2: 31-53.

Roderjan, C.V., Galvão, F., Kuniyoshi, S.Y. \& Hatschbach, G.G. 2002. As unidades fitogeográficas do Estado do Paraná, Brasil. Ciência \& Ambiente 24: 75-92.

Rondon-Neto, R.M., Kozera. C., Andrade. R.R., Cecy. A.T., Hummes. A.P., Fritzsons. E., Caldeira. M.V.W., Maciel. M.N.M. \& Souza. M.K.F. 2002a. Caracterização florística e estrutural de um agrupamento de Floresta Ombrófila Mista em Curitiba. PR - Brasil. Floresta 32: 3-16.

Rondon-Neto, R.M., Watzlawick, L.F., Caldeira. M.V.W. \& Schoeninger, E.R. 2002b. Análise florística e estrutural de um fragmento de Floresta Ombrófila Mista Montana, Situada em Criúva, RS - Brasil. Ciência Florestal 12: 29-37.

Sanquetta, C.R. \& Mattei, E. 2006. Situação dos remanescentes da floresta de araucária no Brasil. Perspectivas de recuperação e manejo sustentável das florestas de araucária. Multi-Graphic, Curitiba. 
Seger, C.D., Dlugosz, F.L., Kurasz, G., Martinez, D.T., Ronconi, E., Melo, L.A.N., Bittencourt, S.M., Brand, M.A., Carniatto, I., Galvão, F. \& Roderjan, C.V. 2005. Levantamento florístico e análise fitossociológica de um remanescente de Floresta Ombrófila Mista localizado no município de Pinhais, Paraná-Brasil. Floresta 35: 291-301.

Seibert, C.L., Negreiros, O.C., Bueno, R.A., Emerich, W., Moura-Netto, B.V., Marcondes, M.A.P, Cesar, S.F., Guillanimon, J.R., Montagna, R.A.A., Barreto, J.R., Oliveira, M.C. \& Godoi, A. 1975. Plano de manejo no Parque Estadual de Campos de Jordão. Boletim Técnico do Instituto Florestal de São Paulo 19: 1-153.

Sentelhas, P.C., Pereira, A.R., Marin, F.R., Angelocci, L.R., Alfonsi, R.R., Caramori, P.H. \& Swart, S. 1999. Balanços Hídricos Climatológicos do Brasil - 500 Balanços Hídricos de Localidades Brasileiras. ESALQ, Piracicaba.

Shepherd, G.J. 1994. FITOPAC: Manual do Usuário. Universidade Estadual de Campinas, Campinas.

Silva, D.W. 2003. Florística e Fitossociologia de dois remanescentes de Floresta Ombrófila Mista (Floresta com Araucaria) e Análise de duas populações de Araucaria angustifolia (Bertol.) O. Kuntze na região de Guarapuava, PR. Tese de Doutorado, Universidade Federal de São Carlos, São Carlos.

Silva, M.M., Ganade, G.M.S. \& Backes, A. 2010. Regeneração natural em um remanescente de Floresta Ombrófila Mista, na Floresta Nacional de São Francisco de Paula, Rio Grande do Sul, Brasil. Pesquisas (Série Botânica: 61). Instituto Anchietano de Pesquisas, São Leopoldo.

Siqueira, E. 2006. História ecológica da floresta de Araucaria durante o QuaternárioTardio no setor sul da serra da Mantiqueira: análises sedimentológicas e palinológicas na regiãode Monte Verde (MG). Tese de Mestrado.Universidade de São Paulo, São Paulo.

SMA. 2004. Espécies da flora ameaçada de extinção no Estado de São Paulo. Diário Oficial, São Paulo, 22 de set. 2004, seção 5, pp. 23.

Soares, C.P.B., Paula Neto, F. \& Souza, A.L. 2007. Dendrometria e inventário florestal. Editora UFV, Viçosa.
Sokal, R.R. \& Rohlf, J.E. 1981. Biometry - the principlesand practice of statistics in biological research. W.H. Freeman and Co., San Francisco.

Solórzano-Filho, J. A. \& Kraus, J. E. 1999. Breve história das matas de Araucária. Forest 99 1999: 37-47.

Sonego, R.C., Backes, A.E. \& Souza, A.F. 2007. Descrição da estrutura de uma Floresta Ombrófila Mista, RS, Brasil, utilizando estimadores não-paramétricos de riqueza e rarefação de amostras. Acta Botanica Brasilica 21: 943-955.

Souza. V.C. \& Lorenzi. H. 2008. Botânica sistemática: Guia ilustrado para identificação das famílias de Angiospermas da flora brasileira. baseado em APG II. Instituto Plantarum, Nova Odessa.

Struffaldi-De-Vuono, Y. 1985. Fitossociologia do estrato arbóreo da floresta da Reserva Biológica do Instituto de Botânica (São Paulo. SP). Tese de Doutorado, Universidade de São Paulo, São Paulo.

Tabarelli, M. \& Mantovani, W. 1999. A riqueza de espécies arbóreas na floresta atlântica de encosta no Estado de São Paulo (Brasil). Revista Brasileira de Botânica 22: 217-223.

Valente, T.P., Negrelle, R.R.B. \& Sanquetta, C.R. 2010. Regeneração de Araucaria angustifolia em três fitofisionomias de um fragmento de Floresta Ombrófila Mista. Iheringia, Série Botânica 65: 17-24.

Valentin, J.L. 2000. Ecologia numérica: uma introdução à analise multivariada de dados ecológicos. Interciência, Rio de Janeiro.

Veloso, H.P. 1992. Sistema fitogeográfico. In: H.P. Veloso (org.). Manual técnico da vegetação brasileira. Instituto Brasileiro de Geografia e Estatística, Rio de Janeiro, pp. 9-38.

Watzlawick, L.F., Sanquetta, C.R., Valério, A.F. \& Silvestre R. 2005. Caracterização da composição florística e estrutura de uma Floresta Ombrófila Mista, no município de General Carneiro (PR). Ambiência Revista do Centro de Ciências Agrárias e Ambientais 1: 229-237.

Whittaker, R.H. 1972. Evolution and measurement of species diversity. Táxon 21: 213-251.

Windisch, P.G. 2002. Fern conservation in Brazil. Fern Gazette 16: 295-300. 
